\title{
Fairness and annuity divisors for notional defined contribution pension schemes
}

\author{
María del Carmen Boado-Penas ${ }^{1 \star}$, Steven Haberman ${ }^{2}$ and Poontavika Naka ${ }^{3}$ \\ ${ }^{1}$ Institute for Financial and Actuarial Mathematics (IFAM), University of Liverpool, UK, ${ }^{2}$ Faculty of Actuarial Science and \\ Insurance, Cass Business School, City, University of London, UK and ${ }^{3}$ Department of Statistics, Chulalongkorn Business \\ School, Chulalongkorn University, Thailand \\ ${ }^{*}$ Corresponding author. Email: carmen.boado@liverpool.ac.uk
}

(Received 23 March 2018; revised 13 September 2020; accepted 30 September 2020; first published online 29 October 2020)

\begin{abstract}
The use of a gender-neutral annuity divisor introduces an intra-generational redistribution from shortlived towards long-lived individuals; this entails a transfer of wealth from males to females and from low socioeconomic groups to high socioeconomic groups. With some subpopulations consisting of females from low socioeconomic groups (or males from high groups), the net effect of the redistribution is unclear. The study aims to quantify the lifetime income redistribution of a generic NDC system using two types of divisor - the demographic and the economic - to compute the amount of an initial pension. With this in mind, the redistribution (actuarial fairness) among subpopulations is assessed through the ratio between the present value of expected pensions received and contributions paid. We find that all subgroups of women and men with high educational attainment benefit from the use of the unisex demographic divisor. This paper also shows that the value of the economic divisor depends markedly on population composition. When mortality differentials by gender and level of education are considered, economic divisors are mostly driven by the longevity effect corresponding to gender.
\end{abstract}

Key words: Annuity divisor; mortality differentials; notional defined contribution; public pension; redistribution; socioeconomic groups

JEL classification: D31; H55; J11; J26

\section{Introduction}

Notional defined contribution (NDCs) schemes have been successfully implemented since the mid-1990s in several European countries such as Italy, Latvia, Norway, Poland and Sweden (Gronchi and Nistico, 2006; Chłoń-Domińczak et al., 2012). They are also found in Kyrgyzstan, Mongolia, Russia, Greece, Egypt, while China is seriously considering the introduction of this NDC scheme (Holzmann et al., 2012; Holzmann, 2017).

NDC pension schemes attempt to reproduce the logic of a defined contribution pension plan where the pension depends on contributions and investment returns - but within a pay-as-you-go (PAYG) framework (Vidal-Meliá et al., 2010) where contributions from current workers are used to pay for pension benefits of current pensioners. For this reason, these are also known as defined contribution unfunded pension schemes. The notional account is a virtual one that records individual contributions, together with the fictitious return that they generate throughout each contributor's working life. The return that contributions earn is calculated based on a macroeconomic index that tries to reflect the financial health of the system (i.e., changes in salaries and GDP growth), not market returns. The account balance is called notional because it is only used for record keeping (i.e., the 
system does not invest funds as the scheme is based on PAYG financing). Upon reaching retirement, the accumulated notional capital is divided by a so-called 'annuity divisor' to obtain a lifelong annuity according to actuarial practice.

Given that women, on average, live longer than males, this 'annuity divisor' could be designed by using gender-specific life tables. However, on the basis of gender equity, all countries with NDCs in place use unisex (also called gender-neutral) survival probabilities to compute the 'annuity divisor', instead of using gender-specific probabilities. These unisex probabilities are calculated by averaging the survival probabilities of both genders. The annuity divisor - also called the demographic (annuity) divisor - takes into account the remaining lifetime at retirement and its value depends on unisex probabilities of survival for the retired cohort, discount rates and the rate of indexation of pensions. Consequently, the use of unisex life expectancy introduces an explicit intra-generational redistribution income is transferred across groups within the same generation - from short-lived towards long-lived individuals, entailing a transfer of wealth from males who on average live shorter lives to females who live longer (Palmer, 2006; Alho et al., 2013; James, 2013). ${ }^{1}$

Another element of heterogeneity in life expectancy arises from socio-economic class - normally assessed through income, education or occupation. A close link between the level of education and mortality has been well documented (Borrell et al., 1999; Huisman et al., 2004; Lleras-Muney, 2005; Miech et al., 2011; Kaplan et al., 2014). The evidence suggests that mortality rates are negatively correlated with socio-economic status (i.e., individuals with higher socioeconomic status live longer than those belonging to lower socioeconomic groups and the size of mortality differences across subgroups has increased over time). In this line, Whitehouse and Zaidi (2008) and Ayuso et al. (2016) provide comprehensive reviews of mortality differentials across socioeconomic groups and the implications of heterogeneity for pension reform and design. However, the net effect of income redistribution between subpopulations considering both gender and socioeconomic status is not clear for some subgroups, such as females with low socioeconomic status or men with high socioeconomic status.

Although the evaluation of redistributive effects on the pension system has attracted wide attention among scholars, there has been little recent literature on lifetime income redistribution under an NDC scheme. ${ }^{2}$ Several studies focus on the comparison of distributional impacts between the old defined benefit and the new NDC scheme. ${ }^{3}$ Also, other related researches investigate the income redistribution occurring from mortality differentials across subpopulations when annuities are priced uniformly under social insurance programmes with mandatory retirement saving accounts (Brown, 2002, 2003; Gong and Webb, 2008; Finkelstein et al., 2009) and collective pension schemes (Hári et al., 2006; Hoevenaars and Ponds, 2008; Bonenkamp, 2009).

Existing literature has no in-depth analysis with respect to the magnitude and the direction of the intra-generational transfers under a generic NDC pension scheme, and we intend to fill this gap. We therefore aim to quantify the redistribution arising from the use of gender-neutral annuity divisors for various socioeconomic groups. In this study, each subpopulation is distinguished by gender and level of educational attainment to measure cross-gender redistribution - between males and females - and inter-educational redistribution - among individuals with different levels of education.

The level of education attainment can capture both direct and indirect effects on mortality. Typically, people with a higher level of educational attainment are less likely to smoke, be obese or be heavy drinkers and are more likely to drive safely, live in a safe house or use preventive care. Hence, this group of people are likely to live longer than those with a lower level of education attainment (Friedman et al., 1995; Kern and Friedman, 2008; Cutler and Lleras-Muney, 2010). In addition,

\footnotetext{
${ }^{1}$ It is worth pointing out that, even in the case of gender-specific survival probabilities, redistribution would always exist from shorter-lived towards longer-lived individuals.

${ }^{2}$ See the works on measuring distributional effects in the pension system, e.g., Cubeddu (2000), Börsch-Supan and Reil-Held (2001), Gustman and Steinmeier (2001), Coronado, Fullerton, and Glass (2002), Barnay (2007), Cremer et al. (2010), Forteza and Ourens (2012), Le Garrec (2012), Gustman et al. (2013), Platanakis and Sutcliffe (2016).

${ }^{3}$ See Borella (2004), Borella and Coda Moscarola (2006) and Belloni and Maccheroni (2013) for the Italian case.
} 
the level of education can be used as a proxy for an individual's lifetime resources since people with higher levels of educational attainment earn, on average, higher incomes (Brown, 2003). The full life cycle is incorporated in the analysis, rather than annual effects, by using a particular indicator, namely the present value ratio that enables us to assess the expected money's worth of participation in the pension system. Another relevant aspect is the analysis of the impact of the inclusion or non-inclusion of the survivor dividend on fairness between individuals belonging to different subgroups.

In addition to focusing on the effect of the demographic annuity divisor related to remaining life expectancy, we examine the distributional impact of an alternative divisor - an economic annuity divisor. The economic annuity divisor reflects the expected number of years that the pension benefits will be disbursed rather than the number of years that a person will survive.

This paper is inspired by the experience of the Swedish NDC pension scheme $e^{4}$ mainly for two main reasons (Swedish Pensions Agency, 2019). First, Sweden is the only country that keeps track of the survivor dividend, i.e., notional account values of the deceased, and distributes it among the survivors of the same birth cohort. Hence, this component constitutes part of the accumulated notional capital used to calculate the value of the initial pensions when people retire. Second, the Swedish NDC scheme is the only one that uses the economic divisor - although not directly in the calculation of the initial pension - as an annuity divisor. In particular, the economic divisor is currently applied to the valuation of liabilities in the Swedish NDC scheme and is associated with the size of pensions and the expected number of years for which the pension will be disbursed. ${ }^{5}$

In this paper, we assess the redistribution (actuarial fairness) among subpopulations in NDC schemes using the ratio between the present value of expected pensions received and contributions paid. Gender- and education-specific cohort life tables are also constructed for use in the computations of the annuity divisors and the expected lifetime income cash flows. We find that all subgroups of women and men with high educational attainment benefit from the use of the unisex demographic divisors - both the demographic and most of the economic divisors proposed. Surprisingly, when the survivor dividend is included, the present value ratio decreases for males when the retirement age increases as higher values of accumulated balances do not compensate for the shorter life span. Economic divisors depend on the composition of the population. In this paper, we show that when mortality differentials by gender and level of education are considered, the economic divisors are mostly driven by the longevity effect corresponding to gender.

The paper is organised as follows; Section 2 describes the framework of a generic NDC scheme, including how to calculate notional capital and annuity divisors. This section also presents a simple example to illustrate the calculation of demographic and economic divisors. Section 3 presents the methodology to model mortality heterogeneity across socioeconomic groups. Section 4 discusses the measurement of income redistribution under the pension scheme with gender-neutral annuity pricing when heterogeneity in mortality exists in the population. The subsequent section provides a numerical illustration of the money's worth for each subpopulation under different scenarios. The paper ends with the conclusion and contains two appendices in which we present mathematical formulae for the notional account balance and the annuity divisors and technical details on the 'stratified Lee-Carter' for mortality rates.

\footnotetext{
${ }^{4}$ In practice, Sweden has gone beyond the NDC system that it implemented in 2001, in the sense that an income statement and a balance sheet are annually published with the aim of analysing the system's solvency. Even so, an automatic balancing system that reduces the growth of the liabilities is triggered if the plan is not fully solvent. Sweden is claimed to be the only NDC country whose pension is financially sustainable over the long term in the sense that it is not necessary to make changes to the contribution rate. For interested readers, please see Boado-Penas and Vidal-Meliá (2012) and Vidal-Meliá et al. (2010).

${ }^{5} \mathrm{We}$ acknowledge that, although the economic divisor is not related to intragenerational redistribution among subgroups, it is interesting to analyse its impact on the fairness of the different subgroups in the population. Also, understanding the economic divisor and the different possibilities for its design can be of vital importance especially in countries with a high degree of income inequality.
} 


\section{An NDC framework}

A generic NDC scheme, in principle, is a combination of a financial traditional defined contribution (DC) pension scheme and a PAYG financing (i.e., contributions from current workers are used to pay for pension benefits of current pensioners). As in the common DC plan, participants contribute a fixed fraction of earnings throughout their working life; however, the account balances under the NDC system are fictitious (or notional) since no actual money is accumulated, and so the individual effectively acquires a series of individual claims on the public pension budget. The return on these contributions, in contrast to a financial defined contribution scheme, is a notional interest rate created by the government, generally linked to wage growth or GDP growth rather than a return on financial assets.

The amount of pension benefits under an NDC pension scheme is based on the concept of an individual lifetime account. At retirement, the amount of the account balance is converted into a lifetime pension according to standard actuarial practice. The initial pension at retirement is expressed in the general form as:

$$
\text { Initial pension at retirement }=\frac{\text { Accumulated notional capital }}{\text { Annuity divisor }} .
$$

\section{- Notional capital}

Under an NDC scheme, the individual notional account grows with new contributions plus (notional) returns on the account. Additionally, among countries implementing this system, only Sweden distributes the notional capital of persons who die during the accumulation phase to the account values of survivors belonging to the same birth cohort. This capital, known as 'inheritance gains' or the 'survivor dividend', constitutes a part of the notional capital used to calculate the initial pension when people retire. ${ }^{6}$ Following Boado-Penas and Vidal-Meliá (2014), the calculation of the accumulated capital at retirement age with both inclusion and non-inclusion of the survivor dividend is described in Appendix A. In particular, see equations (A.1) and (A.2) for technical details about the calculation of the accumulated notional capital with and without the inclusion of the survivor dividend.

\section{- Annuity divisors}

In this paper, we study two different types of annuity divisor. First, in Appendix A, we describe the demographic divisor that takes into account the remaining future lifetime at retirement (equation A.4). In practice, the annuity divisors are equal for both genders, being based on unisex life tables for that cohort. ${ }^{7}$ Second, the Swedish NDC scheme is the only one where the economic divisor is applied to calculate the pension liability of retirees. For the calculation of the economic annuity divisor, both the size of pensions and the pay-out period are considered rather than the number of people who are surviving. The mathematical formula for the economic divisor associated with the expected number of years of pension disbursements is expressed in equation (A.5) of Appendix A.

- Calculation of divisors: an example with four periods

\footnotetext{
${ }^{6}$ This entitlement, Chłon'-Domińczak et al. (2012), is different from the inheritance options in a pre-funded scheme, where the assets of deceased participants are distributed to inheritors. For more details of the survivor dividend in the Swedish NDC system, see Boado-Penas and Vidal-Meliá (2014), Arnold et al. (2016), and Vidal-Meliá et al. (2016).

${ }^{7}$ The formulae of the annuity divisor are differentiated among countries; for example, in Latvia and Poland (called a $G$-value), this factor corresponds to the life expectancy of the retirees in the individual's birth cohort at retirement age. In Italy and Sweden, the divisor includes the assumed rate of real GDP growth or wage growth with $1.5 \%$ in Italy and $1.6 \%$ in Sweden, respectively (Chłoń-Domińczak et al. 2012).
} 
This section presents a simple illustration of the calculation of the demographic and economic divisor for a cohort that joins the labour market at age 0 . In this model, the demographic-financial structure over time for this cohort is given by:

(1) Age:

$$
\overbrace{0,1,}^{\text {Contributors' ages }} \underbrace{2,3}_{\text {Pensioners' ages }} .
$$

(2) The number of individuals at age 0 is 100 . Unisex probability of survival at retirement age (i.e., age 2) is 1 while the probability of survival to age 3 is 0.5 . All individuals are dead by age 4 .

(3) Average salary is constant and given by 100 monetary units. Contribution rate is equal to $10 \%$ of salary.

(4) For simplicity, we assume that the notional rate, the indexation rate of pensions and the discount rate are equal to zero.

Under this setting, the total accumulated notional capital for all individuals at retirement age is equal to 20 and the unisex demographic annuity divisor is equal to $1.5{ }^{8}$ Consequently, the average pension per individual equals to 13.33 .

In practice, salaries and probabilities of survival are different among populations. We assume that the average salary for women is equal to 5 with a probability of survival to age 3 of 0.6 while the average salary for men is 15 with a probability of survival to age 3 of 0.4 . Also, we assume the proportions of men and women in the population are equal. In this case, the accumulated salary per man (woman) is 30 (10) while the amount of the pension using the unisex annuity divisor is 20 (6.67).

The economic divisor considers both differences in pension level and the composition of the population. In the economic divisor calculation, the probabilities of survival are weighted by the pension disbursements so this divisor represents the expected number of years of pension payments, i.e., 1.45. ${ }^{9}$ The amount of the pension would then increase for both men and women if the economic divisor is used. If the probability of survival for women (men) is $0.4(0.6)$, the value of the economic divisor would be 1.55 . Consequently, we can see that the composition of the population has an impact on the value of the divisor and on the amount of the pension paid to the individuals. With no differences in pension levels and in the composition of population among groups, both divisors should be equal.

\section{Modelling and forecasting mortality heterogeneity across socioeconomic groups}

Some studies have applied survival models under different mortality laws (e.g., Gompertz, Makeham, Perks and Makeham-Perks, etc.) and generalised linear models to assess the level of mortality differentials but ignoring mortality improvement by socioeconomic profiles and projection of their future evolution. ${ }^{10}$ When projecting the heterogeneity in mortality between socioeconomic groups (e.g., income, occupation or level of education), we need models that enable the capturing of both differentials in mortality levels and in mortality improvements between subpopulations.

Several papers have used multiple population extensions of the Lee-Carter Model (Lee and Carter, 1992) which allow mortality modelling and forecasting for two or more related populations simultaneously. For instance, some papers study the quantification of mortality differentials across countries (Li and Lee, 2005; Li and Hardy, 2011; Enchev et al., 2017), regions within a country (Debón et al.,

\footnotetext{
${ }^{8}$ The unisex annuity divisor is calculated as $1+0.5=1.5$

${ }^{9}$ The unisex economic divisor is calculated as $1+(6.67 \times 0.6+20 \times 0.4) /(6.67+20)=1.45$

${ }^{10}$ See Richards (2008) and Madrigal et al. (2011), amongst others.
} 
2011; Danesi et al., 2015) or socioeconomic subgroups (Villegas and Haberman, 2014; van Baal et al., 2016).

The Joint-K model proposed by Carter and Lee (1992) assumes that mortality rates of all subpopulations are jointly driven by a single period index but the age-specific mortality pattern and the agespecific responses to changes in the level of mortality are subgroup-specific. Additionally, Villegas and Haberman (2014) have introduced a relative modelling approach where the mortality of socioeconomic subgroups is modelled relative to the mortality of a larger reference population - generally referred to the national population. Their finding concludes that mortality level differentials have a stronger impact on expectations of life and annuity values than mortality improvement differentials.

In this paper, we employ the extension of the Lee-Carter model, known as the 'stratified LeeCarter' model proposed by Debón et al. (2011) to estimate and forecast age- and gender-specific mortality rates across three levels of education. This model works even with small data sets. ${ }^{11}$ The model assumes that all subpopulations have the same mortality improvements at all times, described by the common factor $\beta_{x}$ and $K_{t}$. In practice, it is unlikely that all subgroups would have the identical tendency; however, the assumption that related populations share a common time trend is the long run is reasonable when the available mortality statistics by educational attainment are limited.

The stratified Lee-Carter model proposed by Debón et al. (2011) can be transformed into the relative modelling approach associated with the reference (national) population and the subpopulation introduced by Haberman et al. (2014).

The mortality of the reference population following the Lee-Carter model can be expressed as follows:

$$
\log m_{x, t}=\alpha_{x}+\beta_{x} K_{t}+\varepsilon_{x, t}
$$

where the central mortality rate at age $x$ in calendar year $t$ for the reference population, $m_{x, t}$, is computed as $m_{x, t}=D_{x, t} / E_{x, t}$. We denote $D_{x, t}$ as the number of deaths of the reference population aged $x$ who die in year $t$ before they reach age $x+1$ and the number of person-years of exposure to risk, $E_{x, t}$, is estimated by the mid-year population at age $x$ in calendar year $t$, equivalently to the average number of individuals aged $x$ over a year. The parameter $\alpha_{x}$ describes the average age-specific mortality pattern. The variable $K_{t}$ is a time-varying mortality index representing the overall change in the level of mortality in year $t$ and $\beta_{x}$ measures deviation of the age-specific mortality level when the time index $K_{t}$ changes.

Given the reference population model and the 'stratified Lee-Carter' model with the same parameter $\beta_{x}$ and $K_{t}$ for all populations, the mortality level differences of the subpopulation $i$ compared to the reference population for age group $x$ can be determined in the form of $\alpha_{x}^{i}$ as follows:

$$
\log m_{x, t}^{i}-\log m_{x, t}=\alpha_{x}^{i}
$$

Using equation (2), the mortality of the subpopulation $i$ can be specified through ${ }^{12}$

$$
\log m_{x, t}^{i}=\alpha_{x}+\alpha_{x}^{i}+\beta_{x} K_{t}
$$

with constraints $\sum_{x \in X} \beta_{x}=1, \sum_{t \in T} K_{t}=0$ and $\sum_{i \in I} \alpha_{x}^{i}=0$ for all $x \in X$ where $m_{x, t}^{i}$ is the central mortality rate at age $x, x \in X:=\left\{x_{1}, \ldots, x_{k}\right\}$, in calendar year $t, t \in T:=\left\{t_{1}, \ldots, t_{n}\right\}$, for subpopulation $i$, $i \in I:=\left\{i_{1}, \ldots, i_{s}\right\}$, and $m_{x, t}^{i}=D_{x, t}^{i} / E_{x, t}^{i}$. The age-specific mortality level in subgroup $i$ is $\alpha_{x}+\alpha_{x}^{i}$. The parameter $\beta_{x}$ represents the age-specific pattern of mortality change for all subpopulations and $K_{t}$ is a

\footnotetext{
${ }^{11}$ Haberman et al. (2014) and Villegas et al. (2017) note the difficulties with the Joint-K model and the relative model approach when dealing with small data sets. In this case, the restricted available data on education-specific mortality rates make it difficult to fit reliably time series models with desirable mean reverting properties.

${ }^{12}$ See Villegas and Haberman (2014) in equation (10).
} 
single-period index driving the mortality trend for all subpopulations. Also, the subgroup $i$ is $L$ for low education, $M$ for medium education and $H$ for high education, respectively. In Appendix B, we present the procedure and technical details for the estimation and projections of the group-specific mortality rates and the construction of the cohort life tables.

\section{Measurement of income redistribution}

Under NDC pension schemes, the amount of the pension depends on the accumulated notional capital together with the return it generates over the contributor's working life. Therefore, NDCs narrow the ratio between benefits and contributions, achieving greater actuarial fairness than the traditional defined benefit schemes. Participants who have paid the same amount of contributions and retire at the same age should be entitled to the same pension benefits, while individuals with longer earnings histories or higher earnings who have been contributing more will receive higher benefits.

A pension scheme is viewed as actuarially fair to an individual (or a group of individuals) with average mortality if the (expected) present value of lifetime contributions for this individual (or group of individuals) is equal to the (expected) present value of pension benefits.

Boado-Penas and Vidal-Meliá (2014) and Alonso-García et al. (2018) have demonstrated that the NDC scheme considering the survivor dividend is actuarially fair - pension rights are equivalent to contributions actually paid - on a cohort basis when the population is closed. Due to heterogeneity in mortality across the population, the use of unisex life expectancy as one factor of the actuarial divisor would introduce explicit income redistribution from high-mortality risk to low-mortality risk groups within the same generation (also known as an intra-generational redistribution). People who expect to live longer would get a higher return of the pension system than those who are expected to die earlier, given that they receive the same amount of initial pension at the same retirement age.

The measurement of lifetime redistribution from an individual's perspective can be investigated through the difference between an individual's lifetime contributions and lifetime retirement benefits - in this way, we would capture the money's worth of participation in the pension system (Börsch-Supan and Reil-Held, 2001; Bonenkamp, 2009; Belloni and Maccheroni, 2013). However, we use a variant based on the principle of relative equivalence, called the benefit to cost ratio (or present value ratio) defined as the ratio between the present value of benefits paid during retirement and the contributions paid during their working career (Brown, 2002, 2003; Liebman, 2002; Borella and Coda Moscarola, 2006; Barnay, 2007; Mazzaferro et al., 2012; Belloni and Maccheroni, 2013). Thus, the ratio shows how much the benefit system returns to the participant for each Euro paid.

A value of one indicates that the system is actuarially fair for an individual (i.e., she receives pension benefits which correspond to her contributions) - by definition, there is no redistribution towards or away from any person (Queisser and Whitehouse, 2006). A value greater (lower) than one indicates that an individual receives more (less) than she has been contributing - an individual faces an expected gain (loss) from the pension system.

The present value ratio (henceforth PVR) for a specific individual, with gender $i$ and level of education $j$, who pays scheme contributions for $n$ years throughout the working life and receives pension benefits $P_{\left(x_{e}+n+k, t+n+k\right)}^{i, j}$ at any age $x_{e}+n+k$ in year $t+n+k$ for $m$ years from retirement age until the maximum age of surviving, is evaluated at the age of entry into the labour market $x_{e}$ in year $t$ and is expressed as

$$
P V R_{\left(x_{e}, t\right)}^{i, j}=\frac{\sum_{k=0}^{m-1} n+k P_{\left(x_{e}, t\right)}^{i, j} \cdot P_{\left(x_{e}+n+k, t+n+k\right)}^{i, j} \cdot \prod_{h=0}^{n+k-1}\left(1+r_{t+h}^{*}\right)^{-1}}{{ }_{0} p_{x_{e}, t}^{i, j} \cdot \pi \cdot s_{\left(x_{e}, t\right)}^{i, j}+\sum_{k=1}^{n-1} k p_{\left(x_{e}, t\right)}^{i, j} \cdot \prod_{h=0}^{k-1}\left(1+r_{t+h}^{*}\right)^{-1} \cdot \pi \cdot s_{\left(x_{e}+k, t+k\right)}^{i, j}},
$$

where ${ }_{k} p_{\left(x_{e}, t\right)}^{i, j}$ denotes the probability that an individual with gender $i$ and level of education $j$, entering into the scheme at age $x_{e}$ in year $t$ will be surviving at age $x_{e}+k$ in year $t+k ; r_{t+h}^{*}$ is the real discount rate 
in year $t+h$ and $\pi \cdot s_{\left(x_{e}+k, t+k\right)}^{i, j}$ is the contribution paid in year $t+k$ for an individual with gender $i$ and education $j$ at age $x_{e}+k$. The contribution is as a fixed fraction $\pi$ of annual earnings (or salary) $s_{\left(x_{e}+k, t+k\right)}^{i}$.

\section{Numerical illustration}

This section presents a numerical example based on the Swedish notional scheme to quantify the redistributive effects between subgroups within the same cohort when unisex divisors are used in the calculation of the initial pension. The sources of Swedish data for this illustration are discussed in the first sub-section while the results are presented in the second sub-section. We also provide a sensitivity analysis with respect to the underlying assumptions.

The Swedish notional scheme is particularly interesting for several reasons. First, as stated in Section 2, Sweden is the only country that distributes the survivor dividend among survivors of the same birth cohort. Our paper also analyses the effects of the survivor dividend on actuarial fairness between individuals belonging to different groups. Second, the Swedish NDC scheme is the only one where the economic divisor is computed to calculate the pension liability to retirees. With this in mind, our paper also analyses the effect of using an economic divisor on the pension amount and studies different possibilities for the design of an economic divisor.

\subsection{Demographic and economic data and other assumptions related to the NDC scheme}

In this subsection, we first describe the demographic and economic data and then other assumptions related to the NDC scheme.

\subsubsection{Demographic and economic data}

- The participants in this study are classified by gender and three groups of educational attainment: low, medium and high level of education. ${ }^{13}$ These persons have differences in terms of income profiles and survival probabilities which are the main factors for determining the direction and magnitude of the intra-generational transfers.

- The cross-sectional average annual income for the Swedish population by age group, gender and level of education in 2013 provided in the Eurostat Database is used. ${ }^{14}$ As shown in Figure 1, the pattern of age-earnings profile is an inverted U-shape where annual income increases in the early stages of a worker's career, peaks around middle-age and finally declines as a worker approaches retirement. Women earn less than men for all educational levels and the gender gap is wider for persons with high school education than for those with advanced degrees

- The mortality data for this analysis consists of national mortality experience for calendar years 1960-2013 covering the age range 25-95 obtained from the Human Mortality Database (HMD), and the subpopulation dataset by educational attainment from Eurostat having a shorter observation period 2009-2013 with the age range 25-95. The set of calendar years of subpopulation data is a subset of the corresponding calendar years in the national population and the set of ages available within each subgroup is a subset of those available in the national population as well.

\subsubsection{Choice of parameters and other assumptions related to the NDC scheme}

In order to make the income redistribution comparable across subgroups, the main assumptions and the data sources used for this numerical example are as follows:

\footnotetext{
${ }^{13}$ According to the International Standard Classification of Education (ISCED 2011) classification, Eurostat provides data by education into three categories: (1) less than primary, primary and lower secondary education (levels 0-2); (2) upper secondary and post-secondary non-tertiary education (levels 3-4); and (3) tertiary education (levels 5-8). We then refer those three groups as low, medium and high level of education, respectively.

${ }^{14}$ We consider the year of 2013 as the base year because the latest data on mortality by socioeconomic status (level of education) provided by Eurostat have been updated until this year.
} 


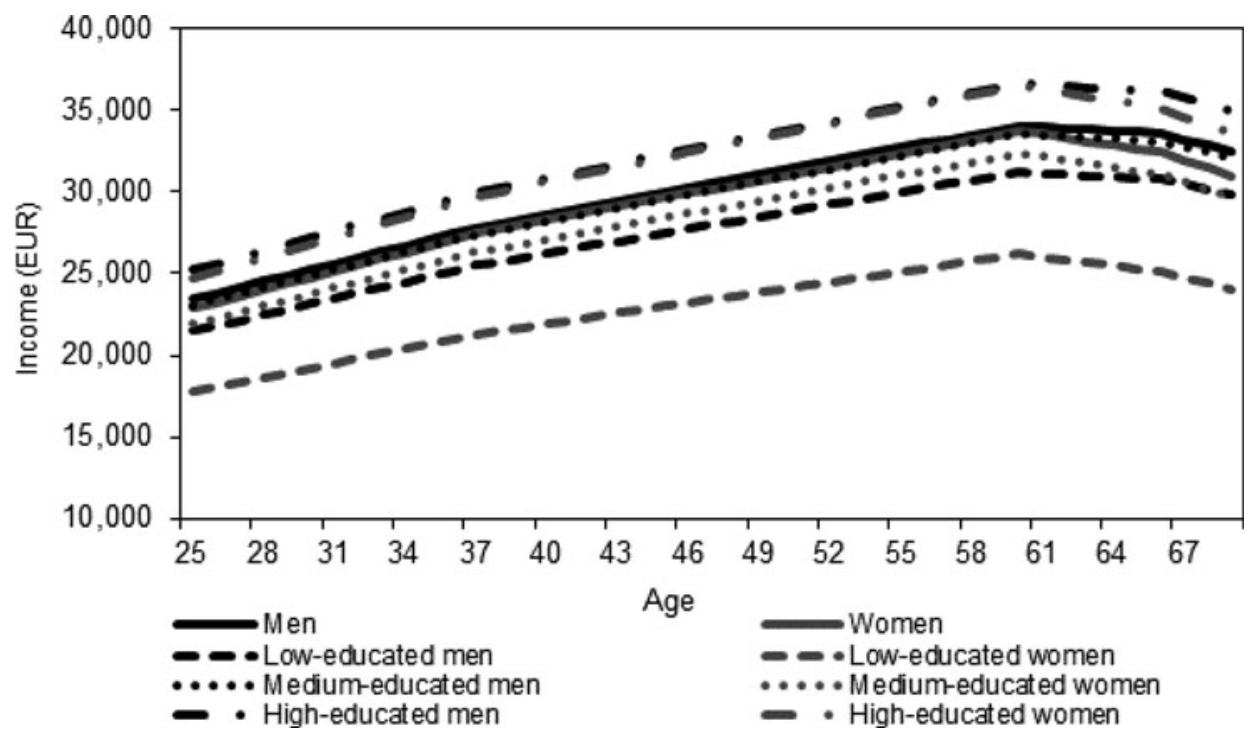

Figure 1. Age-earnings profile estimates during working life, age 25-69 by gender and level of education (in EUR). Source: Authors' calculations derived from Eurostat Database (2017).

- A participant joins the labour market at the age of $x_{e}=25$ in 2013 with a particular level of education that does not change over her working life, and works continuously until retirement age.

- The retirement age $x_{r}$ is equal to 65 . Therefore, a participant pays contributions for $n=40$ years as no unemployment is considered.

- The maximum age that an individual can survive is 95 so the pension benefits are disbursed for $m=31$ years. ${ }^{15}$

- The contribution rate $\pi$ is fixed at $16 \%$ of the individual's earnings. ${ }^{16}$

- The notional rate of return $r$, the discount rate credited in the annuity divisor $r^{\prime}$, the discount rate for the PVR $r^{\star}$ and the indexation rate $\lambda$ to revalue the pension benefits are each set equal to $1.6 \%$ and are assumed to be constant over time. ${ }^{17}$ In the case of the Swedish NDC scheme, both the notional accounts and benefits are indexed in line with changes in average income. ${ }^{18}$ The system is front-loaded, i.e., benefits are calculated considering a discount rate of $1.6 \%$ in the annuity factor. Hence, the indexation of pensions is reduced during the pay-out time by subtracting $1.6 \%$ from the yearly income indexation. ${ }^{19}$ However, in our calculations, we assume that the pensions are constant in real terms so that pensioners maintain their purchasing power. A sensitivity analysis of holding pensions constant in nominal terms is included in Table 6.

\footnotetext{
${ }^{15}$ This is the maximum age at which mortality data by level of education is available in the Eurostat Database.

${ }^{16}$ This value is in line with the contribution rate of the Swedish NDC system.

${ }^{17}$ In general, the notional rate, which is linked to the financial health of the system (i.e., GDP growth), is lower than the discount rate (dynamic efficiency). However, in that case, the PVR would be lower than one, as shown in Table 4: this result does not entail any intragenerational redistribution, but it implies that the individual faces a monetary loss from the pension system (the system is financially inefficient).

${ }^{18}$ The development of income is measured by the income index, which measures the change in average income for individuals who are active in the labour market. See the Swedish Pensions Agency (2019) for more details about the construction of the income index.

${ }^{19}$ In certain situations, Swedish Pensions Agency (2019), exceptions to the regular income indexation of accounts and benefits apply. These exceptions are governed by the ratio of assets to liabilities as provided in the legislation on the balancing mechanism.
} 


\subsection{Results}

In this subsection, we present the results of forecasting mortality per socioeconomic groups and discuss the main results in terms of income redistribution from using the demographic and economic divisors.

- Forecasting mortality across socioeconomic groups

Statistics Sweden reported a period life expectancy at 65 in 2015 was 18.85 years for men and 21.39 years for women. During the last 10 years between 2006 and 2015, the period life expectancy for men has grown by 1.24 years, while the rise for women has been 0.68 years. There are also clear and growing differences in remaining life expectancy among education-specific groups. Specifically, remaining life expectancy at age 65 for males (females) with only compulsory education has increased from 17.02 (20.22) in 2006 to 18 (20.48) in 2015 while the increase from males (females) with a degree is equal to 1.55 (0.94) (The Statistics Sweden, 2016). Hence, in our analysis, the incorporation of group-specific mortality rates is important.

Figure 2 shows the estimated mortality rates in 2013 and projected rates in 2083 across subgroups by applying the 'stratified Lee-Carter' model. ${ }^{20}$ We can see that mortality across subgroups of males (females) is above (below) average mortality. Furthermore, Figure 2 shows that the average mortality rates for men and women are quite close to those with a medium level of education attainment and the mortality of men with high educational attainment and women with low attainment are almost equal to the rates for the overall population.

By 2083, the age-specific mortality rates for all subgroups are projected to have continuously declined, while maintaining the existing patterns of mortality differentials. Also, because of the coherent approach to the modelling of mortality trends for subpopulations, independently for each gender, the projected future subgroup-specific mortality rates do not diverge in the long run and the education- and age-specific mortality rates for each gender deviate consistently from general (reference) mortality rates over time.

\section{- Application of the demographic annuity divisor}

Under the conditions defined above, the unisex demographic annuity divisor for an individual aged 65 is equal to 24.2630 applying the equation (A.4). The values of this annuity divisor across subpopulations compared to the unisex annuity divisor are illustrated in Figure 3. It is noticeable that the values of the demographic divisors for all subgroups of women (men) are greater (lower) than the unisex. The values of the demographic annuity divisors across the subgroups have a pattern that is consistent with mortality.

The money's worth of the pension benefit for an individual who retires at age 65, given the unisex annuity divisor at 24.2630, is measured through the PVR as exhibited in Figure 4. When the survivor dividend is included in the calculation of the initial pension and if there is no heterogeneity in mortality across populations, the PVR is equal to one indicating that the individuals will receive pension benefits identical to what they have contributed over their working lives.

Considering differences in levels of mortality rates per groups, the PVR is higher for females than for males and it increases with the level of education attainment, ranging from 0.9024 for a loweducational attainment male to 1.1127 for a high-educated female worker. Moreover, it is worth noting that all subgroups of females benefit from the use of the unisex demographic divisor, i.e., the PVRs are higher than 1, as shown in Figure 4, which implies that they receive a pension transfer. However, the PVRs for most of the subgroups of males are less than 1, which implies that they pay for a pension transfer.

\footnotetext{
${ }^{20}$ We have also modelled the mortality rate considering mortality improvements among groups by using an extension of Lee and Carter (1992) known as the Joint-K model. However, due to the small data set, the forecasted rates have undesirable properties with, for example, the mortality rates of low-educated people being lower than those for medium-educated.
} 


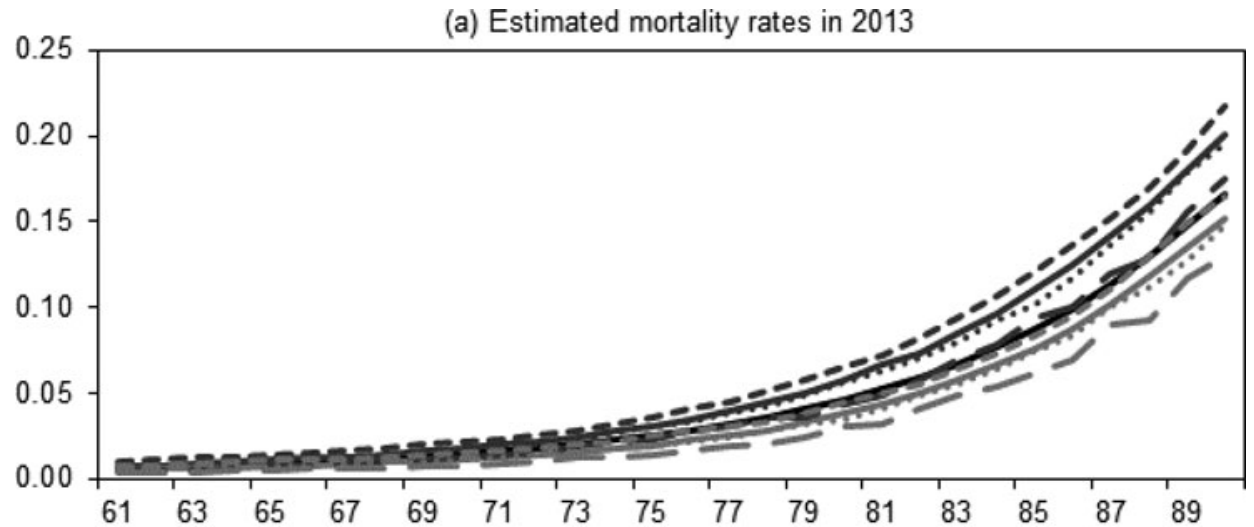

(b) Projected mortality rates in 2083

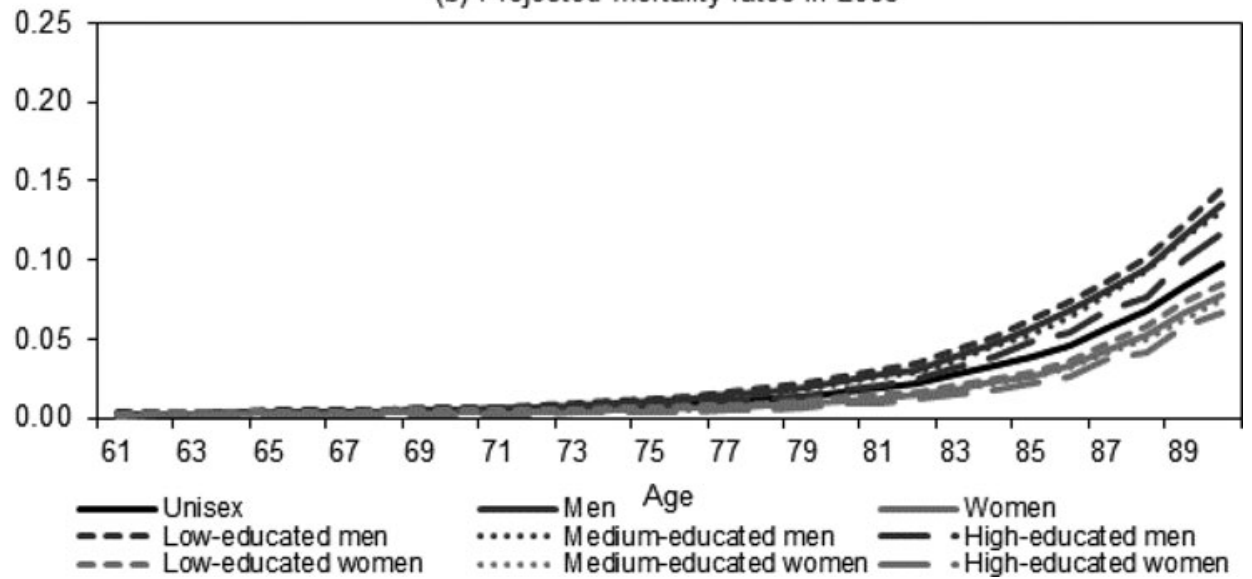

Figure 2. Evolution of mortality rates across gender and three levels of education.

Source: Authors' calculations derived from Human Mortality Database (2017).

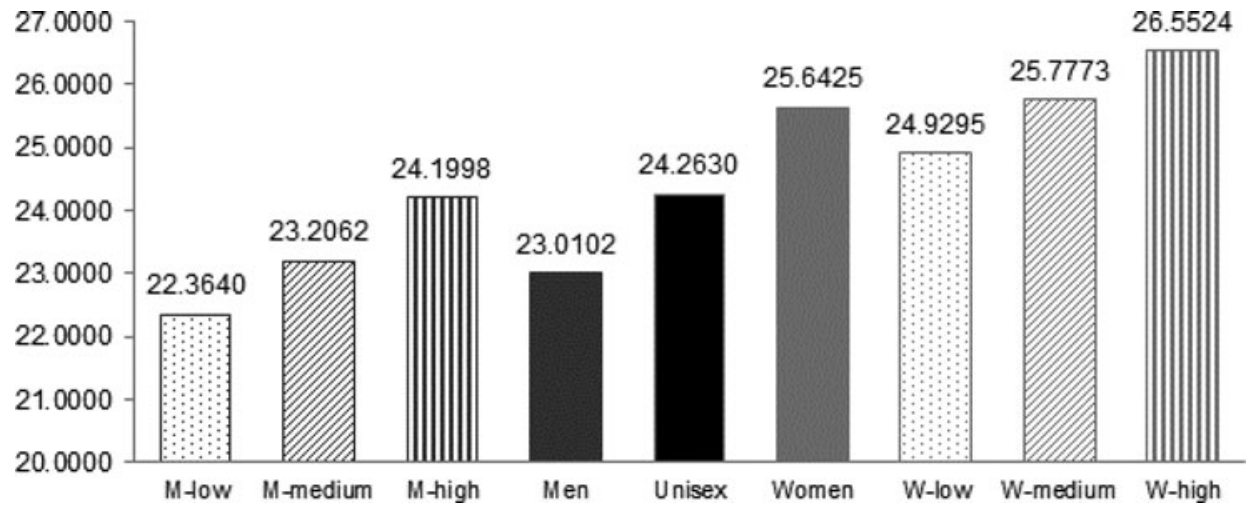

Figure 3. Annuity divisors under the baseline assumptions by gender and education.

Source: Authors' calculations. 


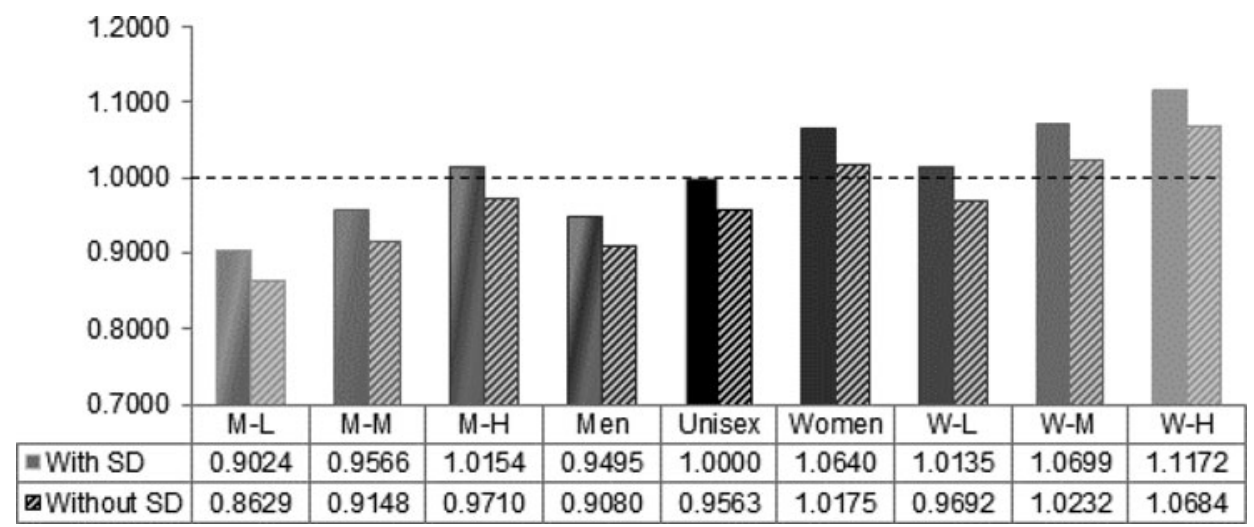

Figure 4. PVR across subpopulations in the cases of notional capital including and excluding survivor dividend. Source: Authors' calculations.

A low-educational attainment male worker is the largest loser, with a PVR of 0.9024 which is $4.96 \%$ less than the PVR for the average man and $9.76 \%$ less than the PVR for the average population, while a high-educational attainment male receives a transfer of income from the system of $1.54 \% .{ }^{21}$ In contrast, all women obtain gains when the unisex demographic annuity divisor is used (i.e., $1.35 \%$ of transfer for a woman with a low educational level, $6.99 \%$ for a medium educational level and $11.72 \%$ for a level of high education attainment).

If the unisex demographic divisor is used, it is remarkable that gender has a larger impact on income redistribution as, even for women with low educational attainment, the PVR is higher than the case for the average population.

In Figure 4, when the survivor dividend is not included in the calculation of the pension benefit, the PVR decreases by $4.37 \%$ for all subgroups. However, even without the inclusion of the survivor dividend, women - specifically with levels of medium and high education attainment - still benefit from the system with a PVR higher than one. ${ }^{22}$

- Application of the economic annuity divisor

The value of the economic divisor for a particular cohort corresponding to equation (A.5) depends on the population composition. Therefore, some plausible assumptions for the size of the different subgroups are needed. As stated in Section 2, the value of the economic divisor increases when the pension disbursement is higher, and the pay-out period is longer.

\footnotetext{
${ }^{21}$ In the case of high-educated men, their specific annuity divisor is slightly lower than the unisex divisor but their PVR is above one. In this case, when using the fair rates for the subpopulation of this group, the divisor is equal to 24.1998 but the accumulated notional capital is lower as the mortality rates for this subgroup are slightly higher than for the general population. As a result, the amount of the pension slightly decreases to 11,933. On the other hand, when using the unisex rates, the divisor increases to 24.2630 but the amount of the accumulated notional capital is also increased - this makes the actual amount of the pension increase (12,117 EUR).

${ }^{22}$ The PVR being lower than one when the survivor dividend is not included does not necessarily reflect any intragenerational redistribution, but it can be caused because the efficiency loss from not including the dividend is greater than the intragenerational redistribution from which the individuals benefit. In fact, if the accumulated capital of the deceased person is not included in the pension calculation then the system is accumulating some reserves with no clear purposes. In Italy, Latvia and Poland, this money is not used and implicitly becomes a component of general public revenues. In Latvia and Poland, these revenues provide the required funding for some unfunded insurance commitments, i.e. legacy costs from the old pension system. Along the same lines, Arnold et al. (2016) show that the reserves that an NDC scheme accumulates when it does not distribute the survivor dividend are much larger than the required amount to finance the longevity risk. Other uses of the survivor dividend could be the financing of a minimum pension or an orphan benefits, among others.
} 
Table 1. PVR for different subgroups when only gender differences in mortality taking into account in the calculation of the divisors

\begin{tabular}{|c|c|c|c|c|c|c|c|}
\hline \multirow{3}{*}{$\begin{array}{l}\text { Sup-group } \\
\text { Divisor }\end{array}$} & \multirow{3}{*}{$\begin{array}{c}\text { Demographic divisor } \\
24.2630\end{array}$} & \multicolumn{6}{|c|}{ Unisex economic divisor } \\
\hline & & \multicolumn{2}{|c|}{ Females $<$ Males } & \multicolumn{2}{|c|}{ Females $=$ Males } & \multicolumn{2}{|c|}{ Females > Males } \\
\hline & & \multicolumn{2}{|c|}{24.1725} & \multicolumn{2}{|c|}{24.3186} & \multicolumn{2}{|c|}{24.4383} \\
\hline \multicolumn{8}{|c|}{ PVR and $\%$ relative change } \\
\hline Men & 0.9495 & 0.9530 & $0.37 \%$ & 0.9473 & $-0.23 \%$ & 0.9427 & $-0.72 \%$ \\
\hline$M-L$ & 0.9024 & 0.9058 & $0.37 \%$ & 0.9003 & $-0.23 \%$ & 0.8959 & $-0.72 \%$ \\
\hline$M-M$ & 0.9566 & 0.9602 & $0.37 \%$ & 0.9544 & $-0.23 \%$ & 0.9497 & $-0.72 \%$ \\
\hline $\mathrm{M}-\mathrm{H}$ & 1.0154 & 1.0192 & $0.37 \%$ & 1.0131 & $-0.23 \%$ & 1.0081 & $-0.72 \%$ \\
\hline Women & 1.0640 & 1.0680 & $0.37 \%$ & 1.0616 & $-0.23 \%$ & 1.0564 & $-0.72 \%$ \\
\hline W-L & 1.0135 & 1.0173 & $0.37 \%$ & 1.0112 & $-0.23 \%$ & 1.0062 & $-0.72 \%$ \\
\hline W-M & 1.0699 & 1.0739 & $0.37 \%$ & 1.0675 & $-0.23 \%$ & 1.0623 & $-0.72 \%$ \\
\hline $\mathrm{W}-\mathrm{H}$ & 1.1172 & 1.1214 & $0.37 \%$ & 1.1146 & $-0.23 \%$ & 1.1092 & $-0.72 \%$ \\
\hline
\end{tabular}

Source: Authors' calculations.

Table 1 shows results when the number of females increases (decreases) by $20 \%$ with respect to the number of males (i.e., $l_{x_{e}+n}^{\text {female }}=1.2 l_{x_{e}+n}^{\text {male }}$ or $l_{x_{e}+n}^{\text {female }}=0.8 l_{x_{e}+n}^{\text {male }}$ ), keeping an equal composition by level of education, that is, one-third of the population for each level of education attainment. If we calculate the economic divisor only considering gender differences in mortality, we see that the value of the economic annuity (i.e., 24.4383) is higher than the demographic divisor when the number of women is larger since the number of years that pensions will be disbursed increases - women generally live longer than men. In contrast, when the number of women is smaller, the value of the economic divisor is lower than the demographic divisor.

Consequently, as shown in Table 1, when the value of the economic divisor is higher (lower), both the amount of the pension and the PVR decrease (increase) compared to the case of using the unisex demographic annuity divisor.

The economic annuity divisor depends on the different sizes of the socioeconomic groups in the total population. In the case that all individuals have a low level of educational attainment, the value of the economic divisor is lower (i.e., 23.5324) than the unisex demographic divisor, as illustrated in Table 2. The use of this economic divisor, which assumes that all individuals have low level of educational attainment, would provide a higher initial pension and consequently all subgroups would benefit from the application of the economic divisor. Conversely, the value of the economic divisor increases when its calculation assumes that all individuals have high level of educational attainment and thus the PVRs for all subpopulations decrease by $4.38 \%$ compared to the case of using the demographic annuity divisor.

Table 3 extends Table 2 and assumes six different compositions of the population when calculating the economic divisor. ${ }^{23}$ As shown in Table 3 , the values of the economic divisor increase with a high level of educational attainment in the population. Specifically, the lowest value of the economic divisor (i.e., 23.9604) results from a combination of males with medium educational attainment and females with low attainment. The values of the economic divisors increase with the level of education and we can categorise the results into three groups depending on the combination of population structure: level of low and medium education (23.9604 and 24.0983), the low and high education (24.5034 and 24.6203), and the medium and high education (24.9382 and 24.9489), respectively.

Furthermore, we show that there are slight differences in the economic divisor values when the population consists of the same combination of levels of educational attainment regardless of gender. For example, the value of the economic divisor for the case of a population consisting of males with high educational attainment and females with low attainment, 24.5034, is quite similar to the case of

\footnotetext{
${ }^{23}$ Table 3 involves women with different education level from men while Table 2 assumes that both males and females have the same level of education.
} 
Table 2. PVR for different subgroups when all individuals are considered to have the same education level (low, medium or high education) for the calculation of the economic divisor

\begin{tabular}{|c|c|c|c|c|c|c|c|}
\hline \multirow{3}{*}{$\begin{array}{l}\text { Sup-group } \\
\text { Divisor }\end{array}$} & \multirow{3}{*}{$\begin{array}{c}\text { Demographic divisor } \\
24.2630\end{array}$} & \multicolumn{6}{|c|}{ Unisex economic divisor } \\
\hline & & \multicolumn{2}{|c|}{ Low education } & \multicolumn{2}{|c|}{ Medium education } & \multicolumn{2}{|c|}{ High education } \\
\hline & & \multicolumn{2}{|c|}{23.5324} & \multicolumn{2}{|c|}{24.4664} & \multicolumn{2}{|c|}{25.3731} \\
\hline \multicolumn{8}{|c|}{ PVR and \% relative change } \\
\hline Men & 0.9495 & 0.9789 & $3.10 \%$ & 0.9416 & $-0.83 \%$ & 0.9079 & $-4.38 \%$ \\
\hline$M-L$ & 0.9024 & 0.9304 & $3.10 \%$ & 0.8949 & $-0.83 \%$ & 0.8629 & $-4.38 \%$ \\
\hline$M-M$ & 0.9566 & 0.9863 & $3.10 \%$ & 0.9486 & $-0.83 \%$ & 0.9147 & $-4.38 \%$ \\
\hline $\mathrm{M}-\mathrm{H}$ & 1.0154 & 1.0469 & $3.10 \%$ & 1.0069 & $-0.83 \%$ & 0.9710 & $-4.38 \%$ \\
\hline Women & 1.0640 & 1.0971 & $3.10 \%$ & 1.0552 & $-0.83 \%$ & 1.0175 & $-4.38 \%$ \\
\hline W-L & 1.0135 & 1.0450 & $3.10 \%$ & 1.0051 & $-0.83 \%$ & 0.9692 & $-4.38 \%$ \\
\hline W-M & 1.0699 & 1.1032 & $3.10 \%$ & 1.0610 & $-0.83 \%$ & 1.0231 & $-4.38 \%$ \\
\hline W-H & 1.1172 & 1.1519 & $3.10 \%$ & 1.1079 & $-0.83 \%$ & 1.0683 & $-4.38 \%$ \\
\hline
\end{tabular}

Source: Authors' calculations.

Table 3. PVR for different subgroups when six different combinations of population are considered for the calculation of the economic divisor

\begin{tabular}{|c|c|c|c|c|c|c|c|}
\hline \multirow{3}{*}{$\begin{array}{l}\text { Sub-group } \\
\text { Divisor }\end{array}$} & \multirow{3}{*}{$\begin{array}{c}\text { Demographic divisor } \\
24.2630\end{array}$} & \multicolumn{6}{|c|}{ Unisex economic divisor } \\
\hline & & ML\&WM & ML\&WH & $M M \& W L$ & MM\&WH & MH\&WL & MH\&WM \\
\hline & & 24.0983 & 24.6203 & 23.9604 & 24.9489 & 24.5034 & 24.9382 \\
\hline \multicolumn{8}{|l|}{ PVR } \\
\hline Men & 0.9495 & 0.9560 & 0.9357 & 0.9615 & 0.9234 & 0.9401 & 0.9238 \\
\hline$M-L$ & 0.9024 & 0.9085 & 0.8893 & 0.9138 & 0.8776 & 0.8935 & 0.8779 \\
\hline$M-M$ & 0.9566 & 0.9631 & 0.9427 & 0.9687 & 0.9303 & 0.9472 & 0.9307 \\
\hline $\mathrm{M}-\mathrm{H}$ & 1.0154 & 1.0223 & 1.0006 & 1.0282 & 0.9875 & 1.0054 & 0.9879 \\
\hline Women & 1.0640 & 1.0713 & 1.0486 & 1.0775 & 1.0348 & 1.0536 & 1.0352 \\
\hline W-L & 1.0135 & 1.0204 & 0.9988 & 1.0263 & 0.9857 & 1.0036 & 0.9861 \\
\hline W-M & 1.0699 & 1.0772 & 1.0544 & 1.0834 & 1.0405 & 1.0594 & 1.0410 \\
\hline W-H & 1.1172 & 1.1248 & 1.1010 & 1.1313 & 1.0865 & 1.1062 & 1.0869 \\
\hline
\end{tabular}

Source: Authors' calculations.

Note: (1) ML\&WM - all men are low-educated and all women are medium-educated; (2) ML\&WH - all men are low-educated and all women are high-educated; (3) MM\&WL - all men are medium-educated and all women are low-educated; (4) MM\&WH - all men are medium-educated and all women are high-educated; (5) MH\&WL - all men are high-educated and all women are low-educated; (6) MH\&WM all men are high-educated and all women are medium-educated.

males with a low attainment and females with a high level, 24.6203. With the same combination of education, the value of the economic divisor is lower for the case where women have a lower level of education than men due to their longer life expectancy.

Notably, a lower value of the economic divisor produces a higher initial pension and it leads to higher values of PVR for all subgroups and vice versa. Although the values of economic divisors vary depending on the population structure, females with medium and high educational attainment benefit from the system no matter which assumptions are used to calculate the divisor.

\subsection{Sensitivity analysis}

This section presents a sensitivity analysis of some variables that might affect the redistribution of the NDC scheme such as the retirement age, notional rate, discount rate and indexation of pensions in payment. A comparative statics framework is used, changing a single variable at a time. The results are illustrated only for the case of the unisex demographic divisor. ${ }^{24}$

\footnotetext{
${ }^{24}$ Although the results of the sensitivity analysis using the economic divisor are different in absolute terms, the conclusions are the same as for the demographic divisor.
} 
Table 4. PVR with different notional rates and \% of relative change compared to the case of using demographic divisor under the main assumptions with $1.6 \%$ of notional rate

\begin{tabular}{|c|c|c|c|c|c|c|c|}
\hline \multirow{3}{*}{$\begin{array}{l}\text { Sub-group } \\
\text { Divisor }\end{array}$} & \multirow{3}{*}{$\begin{array}{c}\text { Demographic divisor } \\
24.2630\end{array}$} & \multicolumn{6}{|c|}{ Notional rate } \\
\hline & & \multicolumn{2}{|c|}{$1 \%$} & \multicolumn{2}{|c|}{$2 \%$} & \multicolumn{2}{|c|}{$3 \%$} \\
\hline & & \multicolumn{2}{|c|}{24.2630} & \multicolumn{2}{|c|}{24.2630} & \multicolumn{2}{|c|}{24.2630} \\
\hline \multicolumn{8}{|c|}{ PVR and $\%$ relative change } \\
\hline Men & 0.9495 & 0.8380 & $-11.74 \%$ & 1.0340 & $8.91 \%$ & 1.2891 & $35.78 \%$ \\
\hline$M-L$ & 0.9024 & 0.7965 & $-11.74 \%$ & 0.9828 & $8.91 \%$ & 1.2252 & $35.78 \%$ \\
\hline$M-M$ & 0.9566 & 0.8443 & $-11.74 \%$ & 1.0418 & $8.91 \%$ & 1.2988 & $35.78 \%$ \\
\hline $\mathrm{M}-\mathrm{H}$ & 1.0154 & 0.8962 & $-11.74 \%$ & 1.1058 & $8.91 \%$ & 1.3786 & $35.78 \%$ \\
\hline Women & 1.0640 & 0.9393 & $-11.72 \%$ & 1.1587 & $8.90 \%$ & 1.4441 & $35.72 \%$ \\
\hline W-L & 1.0135 & 0.8947 & $-11.72 \%$ & 1.1037 & $8.90 \%$ & 1.3755 & $35.72 \%$ \\
\hline W-M & 1.0699 & 0.9445 & $-11.72 \%$ & 1.1651 & $8.90 \%$ & 1.4521 & $35.72 \%$ \\
\hline W-H & 1.1172 & 0.9862 & $-11.72 \%$ & 1.2166 & $8.90 \%$ & 1.5162 & $35.72 \%$ \\
\hline
\end{tabular}

Source: Authors' calculations.

- Changes in retirement age

As seen in equations (A.1), (A.2) and (A.4), when the retirement age increases, the accumulated notional capital increases and the demographic annuity divisor decreases due to a shorter remaining life expectancy. As a result, the amount of the initial pension increases but the effect on the PVR is not clear. When the survivor dividend is not distributed, the PVR would decrease if the retirement age increases (see Figure 5b).

Surprisingly, when the survivor dividend is considered (Figure 5a), the PVRs for all subgroups of females increase with retirement age due to the higher value of the notional capital after the inclusion of the dividend. For males, we can see that the higher values of the accumulated balances - resulting in higher pensions - do not compensate for the shorter lifespan associated with a later retirement and therefore the PVRs decrease when the retirement age increases.

- Changes in notional rate of return

Changes in the notional rate of return have a positive effect on the amount of the accumulated notional capital at retirement age and, as a result, on the direct change in the amount of the initial pension. The expected present value of pension benefits would also increase when the notional rate increases, while the expected present value of contribution payments remains unchanged. Consequently, the PVRs increase with (almost) the same percentage for all subgroups as shown in Table 4 and the results will be more favourable in terms of actuarial gains.

- Changes in discount rate

A higher discount rate will reduce the value of demographic annuity divisors and both the expected present value of contribution payments and pension benefits would decrease. This would lead to the reduction in the PVRs as exhibited in Table 5. The changes in the discount rate have a relatively larger effect on the pension rights of females than males and the same happens for individuals with high educational attainment relative to those with lower levels.

When the discount rate increases to $2 \%$, the cross-gender redistribution declines by $7.97 \%$ for males and by $8.33 \%$ for females and, considering the subgroups among the female population, the PVR drops by $8.30 \%$ for individuals with low-educational attainment and $8.41 \%$ for the ones with high levels. Therefore, an increase in the rate of discount brings about a greater loss for all subgroups of the population.

- Changes in indexation rate 

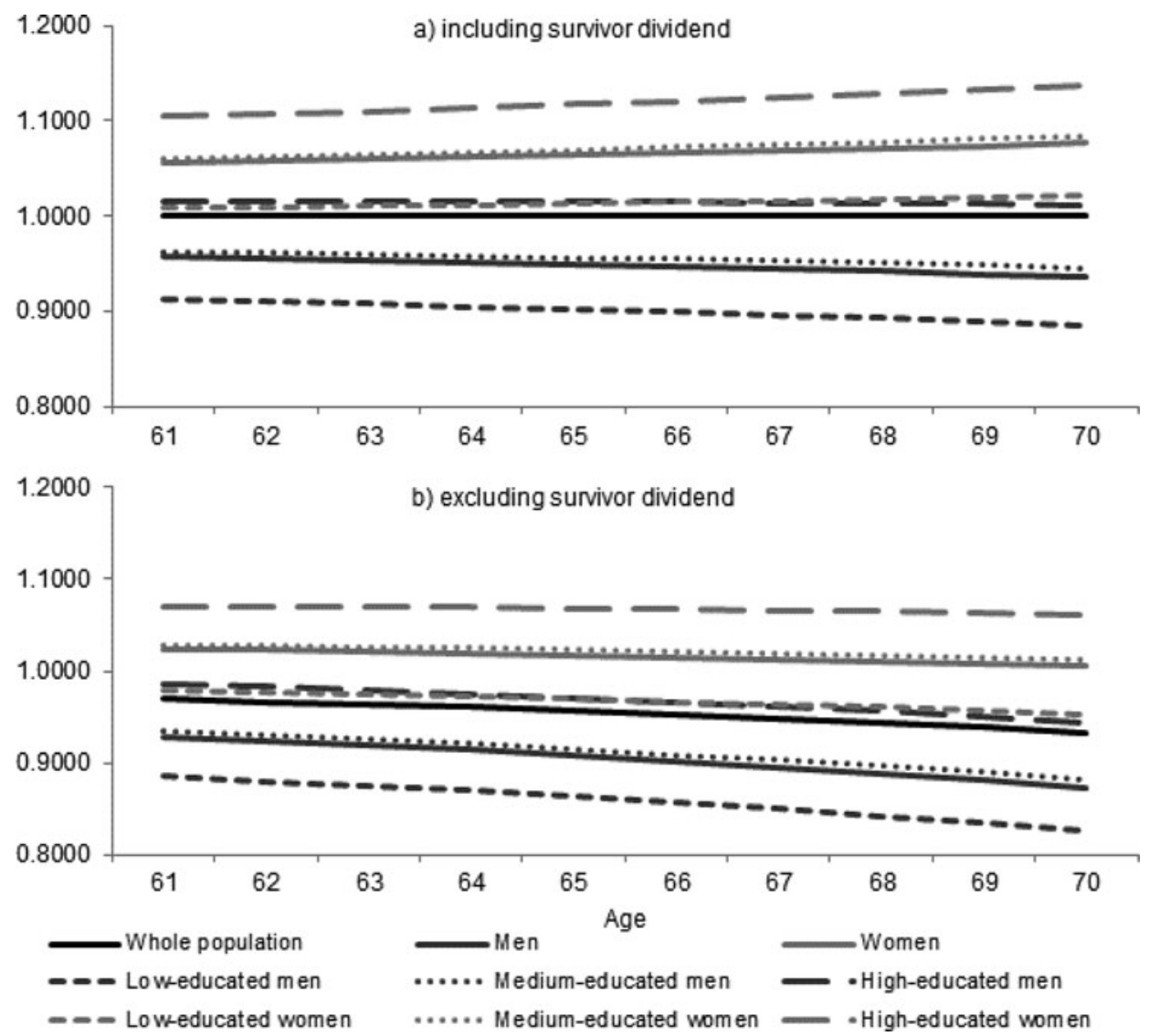

Figure 5. PVR when using unisex demographic divisor with different retirement ages in the case of including and excluding survivor dividend.

Source: Authors' calculations.

Note: Results are based on the main assumptions, but retirement ages vary between 61 and 70 .

Table 5. PVR with different discount rates and \% relative change compared to the case of using demographic divisor under the main assumptions with $1.6 \%$ discount rate

\begin{tabular}{|c|c|c|c|c|c|c|c|}
\hline \multirow{3}{*}{$\begin{array}{l}\text { Sub-group } \\
\text { Divisor }\end{array}$} & \multirow{3}{*}{$\begin{array}{c}\text { Demographic divisor } \\
24.2630\end{array}$} & \multicolumn{6}{|c|}{ Discount rate } \\
\hline & & \multicolumn{2}{|c|}{$1 \%$} & \multicolumn{2}{|c|}{$2 \%$} & \multicolumn{2}{|c|}{$3 \%$} \\
\hline & & \multicolumn{2}{|c|}{26.1943} & \multicolumn{2}{|c|}{23.0914} & \multicolumn{2}{|c|}{20.5127} \\
\hline \multicolumn{8}{|c|}{ PVR and \% relative change } \\
\hline Men & 0.9495 & 1.0719 & $12.89 \%$ & 0.8738 & $-7.97 \%$ & 0.7047 & $-25.78 \%$ \\
\hline$M-L$ & 0.9024 & 1.0181 & $12.83 \%$ & 0.8308 & $-7.94 \%$ & 0.6706 & $-25.69 \%$ \\
\hline$M-M$ & 0.9566 & 1.0805 & $12.95 \%$ & 0.8801 & $-8.00 \%$ & 0.7091 & $-25.87 \%$ \\
\hline $\mathrm{M}-\mathrm{H}$ & 1.0154 & 1.1486 & $13.12 \%$ & 0.9332 & $-8.09 \%$ & 0.7502 & $-26.11 \%$ \\
\hline Women & 1.0640 & 1.2086 & $13.59 \%$ & 0.9754 & $-8.33 \%$ & 0.7793 & $-26.76 \%$ \\
\hline W-L & 1.0135 & 1.1506 & $13.52 \%$ & 0.9294 & $-8.30 \%$ & 0.7433 & $-26.66 \%$ \\
\hline W-M & 1.0699 & 1.2158 & $13.63 \%$ & 0.9806 & $-8.35 \%$ & 0.7830 & $-26.81 \%$ \\
\hline W-H & 1.1172 & 1.2708 & $13.75 \%$ & 1.0232 & $-8.41 \%$ & 0.8157 & $-26.98 \%$ \\
\hline
\end{tabular}

Source: Authors' calculations.

We finally present the distributional effects if we change the rate of indexation used to adjust the amount of pension benefits in each year. A higher indexation rate gives higher values for the annuity divisor and, therefore, the amount of the initial pension would be lower. In particular, in the case that 
Table 6. PVR with different indexation rates and \% relative change compared to the case of using demographic divisor under the main assumptions with $1.6 \%$ of indexation rate

\begin{tabular}{|c|c|c|c|c|c|c|c|c|c|}
\hline \multirow{3}{*}{$\begin{array}{l}\text { Sub-group } \\
\text { Divisor }\end{array}$} & \multirow{3}{*}{$\begin{array}{c}\text { Demographic divisor } \\
24.2630\end{array}$} & \multicolumn{8}{|c|}{ Indexation rate } \\
\hline & & \multicolumn{2}{|c|}{$0 \%$} & \multicolumn{2}{|c|}{$1 \%$} & \multicolumn{2}{|c|}{$2 \%$} & \multicolumn{2}{|c|}{$3 \%$} \\
\hline & & \multicolumn{2}{|c|}{19.9924} & \multicolumn{2}{|c|}{22.5277} & \multicolumn{2}{|c|}{25.5208} & \multicolumn{2}{|c|}{29.0658} \\
\hline \multicolumn{10}{|c|}{ PVR and $\%$ relative change } \\
\hline Men & 0.9495 & 0.9578 & $0.88 \%$ & 0.9527 & $0.34 \%$ & 0.9472 & $-0.23 \%$ & 0.9415 & $-0.84 \%$ \\
\hline$M-L$ & 0.9024 & 0.9133 & $1.21 \%$ & 0.9066 & $0.47 \%$ & 0.8995 & $-0.32 \%$ & 0.8921 & $-1.14 \%$ \\
\hline$M-M$ & 0.9566 & 0.9638 & $0.75 \%$ & 0.9594 & $0.29 \%$ & 0.9547 & $-0.20 \%$ & 0.9497 & $-0.72 \%$ \\
\hline $\mathrm{M}-\mathrm{H}$ & 1.0154 & 1.0181 & $0.27 \%$ & 1.0165 & $0.11 \%$ & 1.0146 & $-0.07 \%$ & 1.0126 & $-0.27 \%$ \\
\hline Women & 1.0640 & 1.0563 & $-0.73 \%$ & 1.0610 & $-0.28 \%$ & 1.0661 & $0.19 \%$ & 1.0713 & $0.68 \%$ \\
\hline W-L & 1.0135 & 1.0091 & $-0.44 \%$ & 1.0118 & $-0.17 \%$ & 1.0147 & $0.12 \%$ & 1.0177 & $0.41 \%$ \\
\hline W-M & 1.0699 & 1.0612 & $-0.82 \%$ & 1.0666 & $-0.31 \%$ & 1.0722 & $0.21 \%$ & 1.0782 & $0.77 \%$ \\
\hline W-H & 1.1172 & 1.1043 & $-1.15 \%$ & 1.1122 & $-0.44 \%$ & 1.1206 & $0.30 \%$ & 1.1293 & $1.08 \%$ \\
\hline
\end{tabular}

Source: Authors' calculations.

there is no indexation - the pension benefits remain constant over time - the unisex annuity divisor decreases from 24.2630 to 19.9924 as illustrated in Table 6 .

However, we show that the PVRs do not change in the same direction for males and females (i.e., PVRs decrease for males and increase for women when the rate of indexation of pension increases). This is due to the fact that the expected present value of pensions for women increases with increases in the value of the indexation rate since this group benefits from having a longer life expectancy than average.

\section{Conclusions}

The use of gender-neutral annuity divisor in the conversion of the accumulated notional capital into a lifetime annuity under the NDC pension scheme introduces an intra-generational income redistribution when heterogeneity in mortality exists in the population. This paper examines the redistributive effects across subpopulations - differentiated by gender and educational attainment - of using a unisex demographic annuity divisor that is related to remaining life expectancy, and an alternative divisor namely the economic annuity divisor that depends on the size of pension disbursements and the payout period.

The value of the alternative divisor, used in Sweden to calculate pension liabilities, depends on the composition of the population. In this respect, for a particular gender or level of education, the value of the economic divisor tends to be higher if the pension system has a larger proportion of the population with low-mortality risk (i.e., females or people with high educational attainment). Moreover, we demonstrate that, when mortality differentials by gender and level of education are taken into account, the economic divisor is mostly driven by the longevity effect corresponding to gender.

Income redistribution is measured through the concept of the money's worth in respect of participation in the pension system on a lifetime basis. As expected, the numerical illustrations strongly confirm the expected transfer of wealth away from high-mortality risk groups to low-mortality risk groups. Also, all subgroups of women and men with high education attainment benefit from the use of unisex annuity divisors - both demographic and most of the economic divisors proposed as their life spans are longer than the average life expectancy. This leads to present value ratios greater than the case for the average population.

The other consequence of using the economic divisor is that, with changes in the value of the economic divisor, the amount of the initial pension and the PVRs would change in the opposite direction with the same relative percentage of change for all subgroups.

In addition, the initial pension taking into account the survivor dividend would create an actuarially fair pension system - an individual will receive pension benefits equivalent to what she has been contributing over her working life - if there is no heterogeneity in mortality across subpopulations. 
Surprisingly, the survivor dividend also produces a trade-off between the PVRs for males and females at the different ages of retirement. Specifically, the PVRs for all subgroups of females increase if the retirement age is delayed due to the higher value of the notional capital distributed which is increased by more capital from deceased participants. In contrast, the higher values of the accumulated balances for males do not compensate for the shorter life span associated with a later retirement and thus the PVRs decrease when the retirement age increases. Furthermore, the distribution of the survivor dividend would reduce the effect of differential mortality on the income transfer since the PVRs, when including the survivor dividend for all subgroups, are higher than those in the case without the survivor dividend.

This paper evaluates income redistribution on a purely financial basis. One potential direction for future research would be to investigate the effect of mortality heterogeneity on the utility gains associated with the use of annuity divisors. Different policy options could also be designed along the contribution-benefit lifecycle with the aim of reducing the distributional effects of the system. There is a limitation of our methodology that we assume that everyone joins the labour market at the same entry age. Another avenue for future work would be to model the entry age for different groups of individuals together with its effects on life expectancy and actuarial fairness. Finally, as a third direction of future research, it would be interesting, following Lindbeck and Persson (2003), to measure the intragenerational redistribution on notional accounts excluding the effects of the financial inefficiency that might be inherent to the system.

Acknowledgements. María del Carmen Boado-Penas is grateful for the financial assistance received from the Spanish Ministry of the Economy and Competitiveness [project ECO2015-65826-P].

\section{References}

Alho J, Bravo J and Palmer E (2013) Annuities and life expectancy in NDC. In Holzmann R, Palmer E and Robalino D (eds), Nonfinancial Defined Contribution Pension Schemes in a Changing Pension World. Volume 2. Gender, Politics, and Financial Stability. Washington, DC: World Bank, pp. 395-436.

Alonso-García J, Boado-Penas MC and Devolder P (2018) Adequacy, fairness and sustainability of pay-as-you-go pension systems: defined benefit versus defined contribution. The European Journal of Finance 24, 1100-1122.

Arnold S, Boado-Penas MC and Godínez-Olivares H (2016) Longevity risk in notional defined contribution pension schemes: a solution. The Geneva Papers on Risk and Insurance - Issues and Practice 41, 24-52.

Ayuso M, Bravo JM and Holzmann R (2016) On the heterogeneity in longevity among socioeconomic groups: scope, trends, and implications for earnings-related pension schemes, IZA Discussion Paper No.10060.

Barnay T (2007) Redistributive impact of differential mortality in the French pay-as-you-go system. The Geneva Papers on Risk and Insurance - Issues and Practice 32, 570-582.

Belloni M and Maccheroni C (2013) Actuarial fairness when longevity increases: an evaluation of the Italian pension system. The Geneva Papers on Risk and Insurance - Issues and Practice 38, 638-674.

Boado-Penas MC and Vidal-Meliá C (2012) The actuarial balance of the pay-as-you-go pension system: The Swedish NDC model versus the US DB model. Chapter 23, In Holzmann R, Palmer E and Robalino D (eds), NDC Pension Schemes in a Changing Pension World, Volume 2: Gender, Politics, and Financial Stability. Washington, DC: The World Bank, pp. 443489. ISBN (paper): 978-0-8213-9478-6 ISBN (electronic): 978-0-8213-9479-3. doi: 10.1596/978-0-8213-9478-6.

Boado-Penas MC and Vidal-Meliá C (2014) Nonfinancial defined contribution pension schemes: is a survivor dividend necessary to make the system balanced? Applied Economics Letters 21, 242-247.

Bonenkamp J (2009) Measuring lifetime redistribution in Dutch occupational pensions. De Economist 157, 49-77.

Borella M (2004) The distributional impact of pension system reforms: an application to the Italian case. Fiscal Studies $\mathbf{2 5}$, 415-437.

Borella M and Coda Moscarola F (2006) Distributive properties of pensions systems: a simulation of the Italian transition from defined benefit to notional defined contribution. Giornale degli Economisti 65, 95-126.

Borrell C, Regidor E, Arias LC, Navarro P, Puigpinós R, Domínguez V and Plasència A (1999) Inequalities in mortality according to educational level in two large southern European cities. International Journal of Epidemiology 28, 58-63.

Börsch-Supan A and Reil-Held A (2001) How much is transfer and how much is insurance in a pay-as-you-go system? The German case. Scandinavian Journal of Economics 103, 505-524.

Brown JR (2002) Differential mortality and the value of individual account retirement annuities. In Feldstein M and Liebman JB (eds), The Distributional Aspects of Social Security and Social Security Reform, NBER Conference Report Series. Chicago and London: University of Chicago Press, pp. 401-440. 
Brown JR (2003) Redistribution and insurance: mandatory annuitization with mortality heterogeneity. Journal of Risk and Insurance 70, 17-41.

Carter LR and Lee RD (1992) Modeling and forecasting US sex differentials in mortality. International Journal of Forecasting 8, 393-411.

Chłoń-Domińczak A, Franco D and Palmer E (2012) The first wave of NDC reforms: the experiences of Italy, Latvia, Poland, and Sweden. In Holzmann R, Palmer E and Robalino D (eds), Nonfinancial Defined Contribution Pension Schemes in a Changing Pension World, Volume 1: Progress, Lessons, and Implementation, Washington, DC: World Bank, pp. 31-84.

Coronado, Fullerton, and Glass (2002) Long-run effects of social security reform proposals on lifetime progressivity. In Feldstein M and Liebman J (eds), The Distributional Aspects of Social Security and Social Security Reform. Chicago: University Chicago Press, pp. 149-204.

Cremer H, Lozachmeur J-M and Pestieau P (2010) Collective annuities and redistribution. Journal of Public Economic Theory 12, 23-41.

Cubeddu L (2000) Intragenerational redistribution in unfunded pension systems. IMF Staff Papers 47, 90-115.

Cutler DM and Lleras-Muney A (2010) Understanding differences in health behaviors by education. Journal of Health Economics 29, 1-28.

Danesi IL, Haberman S and Millossovich P (2015) Forecasting mortality in subpopulations using Lee-Carter type models: a comparison. Insurance: Mathematics and Economics 62, 151-161.

Debón A, Montes F and Martínez-Ruiz F (2011) Statistical methods to compare mortality for a group with non-divergent populations: an application to Spanish regions. European Actuarial Journal 1, 291-308.

Enchev V, Kleinow T and Cairns AJG (2017) Multi-population mortality models: fitting, forecasting and comparisons. Scandinavian Actuarial Journal 2017, 319-342.

Finkelstein A, Poterba J and Rothschild C (2009) Redistribution by insurance market regulation: analyzing a ban on genderbased retirement annuities. Journal of Financial Economics 91, 38-58.

Forteza A and Ourens G (2012) Redistribution, insurance and incentives to work in Latin-American pension programs. Journal of Pension Economics and Finance 11, 337-364.

Friedman HS, Tucker JS, Schwartz JE, Martin LR, Tomlinson-Keasey C, Wingard DL and Criqui MH (1995) Childhood conscientiousness and longevity: health behaviors and cause of death. Journal of Personality and Social Psychology 68, 696-703.

Gong G and Webb A (2008) Mortality heterogeneity and the distributional consequences of mandatory annuitization. Journal of Risk and Insurance 75, 1055-1079.

Gronchi S and Nistico S (2006) Implementing the NDC theoretical model: a comparison of Italy and Sweden. In Holzmann $\mathrm{R}$ and Palmer E (eds), Pension Reform: Issues and Prospects for Non-financial Defined Contribution (NDC) Schemes. Washington, DC: World Bank, pp. 493-515.

Gustman AL and Steinmeier TL (2001) How effective is redistribution under the social security benefit formula? Journal of Public Economics 82, 1-28.

Gustman AL, Steinmeier TL and Tabatabai N (2013) Redistribution under the social security benefit formula at the individual and household levels, 1992 and 2004. Journal of Pension Economics and Finance 12, 1-27.

Haberman S, Kaishev V, Millossovich P, Villegas A, Baxter S, Gaches A, Gunnlaugsson S and Sison M (2014) Longevity basis risk: a methodology for assessing basis risk, Institute and Faculty of Actuaries.

Hári N, Koijen R and Nijman T (2006) The determinants of the money's worth of participation in collective pension schemes, Netspar Working Paper 2006-027: Tilburg.

Hoevenaars RPMM and Ponds EHM (2008) Valuation of intergenerational transfers in funded collective pension schemes. Insurance: Mathematics and Economics 42, 578-593.

Holzmann R (2017) The ABCs of nonfinancial defined contribution (NDC) schemes. International Social Security Review 70, 53-77.

Holzmann R, Palmer E and Robalino D (2012) Nonfinancial Defined Contribution Pension Schemes in a Changing Pension World, Volume 1: Progress, Lessons, and Implementation. Washington, DC: World Bank.

Huisman M, Kunst AE, Andersen O, Bopp M, Borgan JK, Borrell C, Costa G, Deboosere P, Desplanques G, Donkin A, Gadeyne S, Minder C, Regidor E, Spadea T, Valkonen T and Mackenbach JP (2004) Socioeconomic inequalities in mortality among elderly people in 11 European populations. Journal of Epidemiology and Community Health 58, 468-475.

James E (2013) Gender in the (nonfinancial) defined contribution world: issues and options. In Holzmann R, Palmer E and Robalino D (eds), Nonfinancial Defined Contribution Pension Schemes in a Changing Pension World. Volume 2. Gender, Politics, and Financial Stability. Washington, DC: World Bank, pp. 3-33.

Kaplan RM, Spittel ML and Zeno TL (2014) Educational attainment and life expectancy. Policy Insights from the Behavioral and Brain Sciences 1, 189-194.

Kern ML and Friedman HS (2008) Do conscientious individuals live longer? A quantitative review. Health Psychology 27, 505-512.

Lee RD and Carter LR (1992) Modeling and forecasting U.S. Mortality. Journal of the American Statistical Association 87, 659-671. 
Le Garrec G (2012) Social security, income inequality and growth. Journal of Pension Economics and Finance 11, 53-70.

Li JS-H and Hardy MR (2011) Measuring basis risk in longevity hedges. North American Actuarial Journal 15, 177-200.

Li N and Lee R (2005) Coherent mortality forecasts for a group of populations: an extension of the lee-carter method. Demography 42, 575-594.

Liebman JB (2002) Redistribution in the current U.S. Social Security System. In Feldstein M and Liebman JB (eds), The Distributional Aspects of Social Security and Social Security Reform. Chicago: University of Chicago Press, pp. 11-42.

Lindbeck A and Persson M (2003) The gains from pension reform. Journal of Economic Literature 41, 74-112.

Lleras-Muney A (2005) The relationship between education and adult mortality in the United States. The Review of Economic Studies 72, 189-221.

Madrigal AM, Matthews FE, Patel DD, Gaches AT and Baxter SD (2011) What longevity predictors should be allowed for when valuing pension scheme liabilities?. British Actuarial Journal 16, 1-38.

Mazzaferro C, Morciano M and Savegnago M (2012) Differential mortality and redistribution in the Italian notional defined contribution system. Journal of Pension Economics and Finance 11, 500-530.

Miech R, Pampel F, Kim J and Rogers RG (2011) The enduring association between education and mortality: the role of widening and narrowing disparities. American Sociological Review 76, 913-934.

Palmer E (2006) What is NDC? In Holzmann R and Palmer E (eds), Pension Reform: Issues and Prospects for Non-financial Defined Contribution (NDC) Schemes. Washington, DC: World Bank, pp. 17-33.

Pitacco E, Denuit M, Haberman S and Olivieri A (2009) Modelling Longevity Dynamics for Pensions and Annuity Business. New York: Oxford University Press.

Platanakis E and Sutcliffe C (2016) Pension scheme redesign and wealth redistribution between the members and sponsor: the USS rule change in October 2011. Insurance: Mathematics and Economics 69(suppl. C), 14-28.

Queisser M and Whitehouse E (2006) Neutral or Fair?: Actuarial Concepts and Pension-System Design, OECD Social, Employment and Migration Working Papers, No.40.

Renshaw A and Haberman S (2003) Lee-carter mortality forecasting: a parallel generalized linear modelling approach for England and Wales mortality projections. Journal of the Royal Statistical Society: Series C (Applied Statistics 52, $119-137$.

Richards SJ (2008) Applying survival models to pensioner mortality data. British Actuarial Journal 14, 257-303.

Swedish Pensions Agency (2019) Orange Report: Annual Report of the Swedish Pension System 2018, Stockholm: Swedish Pensions Agency.

The Statistics Sweden (2016) Life Expectancy and Mortality in Different Social Groups, Demographic report 2016:2, Stockholm.

van Baal P, Peters F, Mackenbach J and Nusselder W (2016) Forecasting differences in life expectancy by education. Population Studies 70, 201-216.

Vidal-Meliá C, Boado-Penas MC and Settergren O (2010) Instruments for improving the equity, transparency and solvency of pay-as-you-go pension systems: NDCs, Abs and ABMs. In Micocci M, Masala G and Gregoriou GN (eds), Pension Fund Risk Management - Financial and Actuarial Modeling. Chapter 18. New York, USA: Chapman \& Hall/CRC Finance Series, pp. 419-472. ISBN: 9781439817520, ISBN 10: 1439817529.

Vidal-Meliá C, Boado-Penas MC and Navarro-Cabo F (2016) Notional defined contribution pension schemes: why does only Sweden distribute the survivor dividend? Journal of Economic Policy Reform 19, 200-220.

Villegas AM and Haberman S (2014) On the modeling and forecasting of socioeconomic mortality differentials: an application to deprivation and mortality in England. North American Actuarial Journal 18, 168-193.

Villegas AM, Haberman S, Kaishev VK and Millossovich P (2017) A comparative study of two-population models for the assessment of basis risk in longevity hedges. ASTIN Bulletin 47, 631-679.

Whitehouse ER and Zaidi A (2008) Socio-economic Differences in Mortality: Implications for Pensions Policy, OECD Social, Employment and Migration Working Papers, No.71. OECD Publishing.

Wilmoth JR, Andreev K, Jdanov D and Glei DA (2007) Methods protocol for the human mortality database, University of California and Max Planck Institute for Demographic Research. 


\section{Appendix}

\section{A. Mathematical formulae for the notional account balance and the annuity divisors}

- Notional capital, excluding the survivor dividend

If the accumulated survivor dividend is not included, the accumulated notional capital at retirement age $x_{e}+n$ in year $t+n$ for an individual with gender $i$ and level of education $j$, denoted as $K_{\left(x_{e}+n, t+n\right)}^{i, j}$, is calculated ${ }^{25}$ as

$$
K_{\left(x_{e}+n, t+n\right)}^{i, j}=\sum_{k=0}^{n-1} \pi \cdot s_{\left(x_{e}+k, t+k\right)}^{i, j} \cdot \prod_{h=k}^{n-1}\left(1+r_{t+h}\right)
$$

where $i$ denotes the gender indicator with man $(m)$ and woman $(w)$;

$j$ denotes the indicator with respect to educational attainment: low $(L)$, medium $(M)$ and high $(H)$ education;

$n$ represents the number of year that contributions are paid from the age of entry into the labour market $x_{e}$ in year $t$ until reaching retirement age $x_{e}+n$ in year $t+n$;

$\pi \cdot s_{\left(x_{e}+k, t+k\right)}^{i, j}$ is the contribution paid in year $t+k$ for an individual with gender $i$ and education $j$ at age $x_{e}+k$. The contribution is as a fixed fraction $\pi$ of the annual earnings (or salary) $s_{\left(x_{e}+k, t+k\right)}^{i, j}$

$r_{t+h}$ is the annual (notional) rate of return in year $t+h$.

- Notional capital, including the survivor dividend

If the survivor dividend is included, then the amount of notional capital at retirement increases in line with the accumulated survivor dividend at retirement age. The accumulated notional capital including the survivor dividend at retirement age $x_{e}+n$ in year $t+n$ for an individual with gender $i$ and level of education $j$, denoted $K_{\left(x_{e}+n, t+n\right)}^{* i,}$, is calculated as

$$
K_{\left(x_{e}+n, t+n\right)}^{* i, j}=K_{\left(x_{e}+n, t+n\right)}^{i, j}+D_{\left(x_{e}+n, t+n\right)}^{a c}
$$

and

$$
D_{\left(x_{e}+n, t+n\right)}^{a c}=\sum_{k=0}^{n-1} \frac{\pi \cdot s_{\left(x_{e}+k, t+k\right)} \cdot \prod_{h=k}^{n-1}\left(1+r_{t+h}\right)}{n-k P\left(x_{e}+k, t+k\right)}-\sum_{k=0}^{n-1} \pi \cdot s_{\left(x_{e}+k, t+k\right)} \cdot \prod_{h=k}^{n-1}\left(1+r_{t+h}\right),
$$

where $D_{\left(x_{e}+n, t+n\right)}^{a c}$ is the accumulated survivor dividend at retirement age for an individual who has contributed for $n$ years since entering the system;

$s_{\left(x_{e}+k, t+k\right)}$ is the average salary for an individual aged $x_{e}+k$ in year $t+k$;

${ }_{n-k} P\left(x_{e}+k, t+k\right)$ is the probability that an individual aged $x_{e}+k$ in year $t+k$ will be alive at age $x_{e}+n$ in year $t+n$.

- Demographic annuity divisor

The demographic annuity divisor is equivalent to the present value of a whole life annuity-due at retirement age $x_{e}+n$ in year $t+n$ and is calculated as

$$
\begin{aligned}
D D_{\left(x_{e}+n, t+n\right)} & ={ }_{0} P_{\left(x_{e}+n, t+n\right)}+\sum_{k=1}^{m-1}{ }_{k} P_{\left(x_{e}+n, t+n\right)} \cdot \prod_{h=0}^{k-1} \frac{1+\lambda_{t+n+h}}{1+r^{\prime}{ }_{t+n+h}} \\
& =1+\sum_{k=1}^{m-1} \frac{l_{\left(x_{e}+n+k, t+n+k\right)}}{l_{\left(x_{e}+n, t+n\right)}} \cdot \prod_{h=0}^{k-1} \frac{1+\lambda_{t+n+h}}{1+r^{\prime}{ }_{t+n+h}}
\end{aligned}
$$

where pension benefits are disbursed for $m$ years from the retirement age until the maximum age that an individual can survive. The pensions settled after the first payment are revalued by the indexation rate, $\lambda_{t+n+h}$ and discounted with the technical interest rate $r_{t+n+h}^{\prime}$. Also, $l_{\left(x_{e}+n+k, t+n+k\right)}$ is the number of individuals surviving at age $x_{e}+n+k$ in year $t+n+k$.

\footnotetext{
${ }^{25}$ Contributions and pension benefits are assumed to be payable yearly in advance.
} 

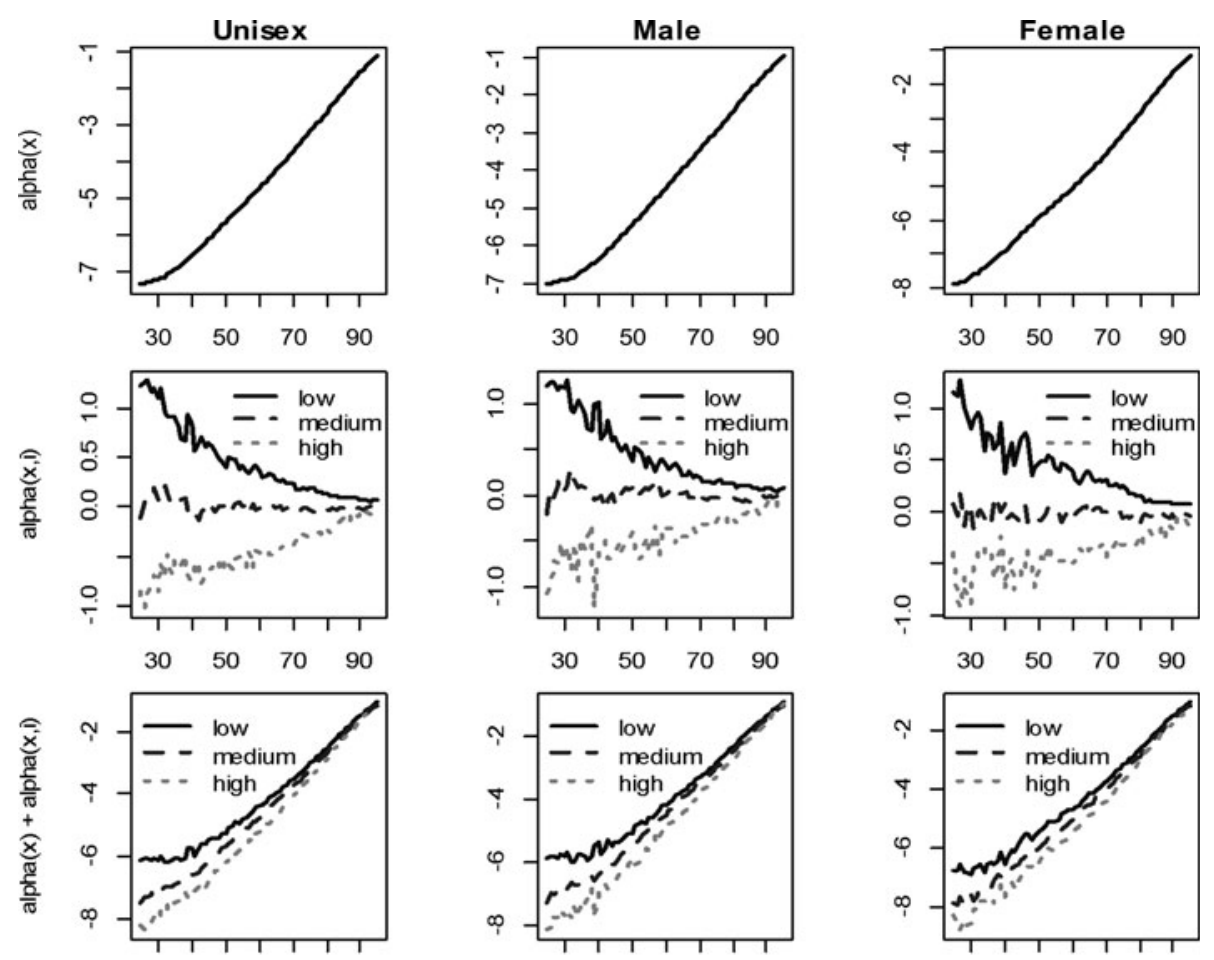

$30 \quad 50 \quad 70 \quad 90$
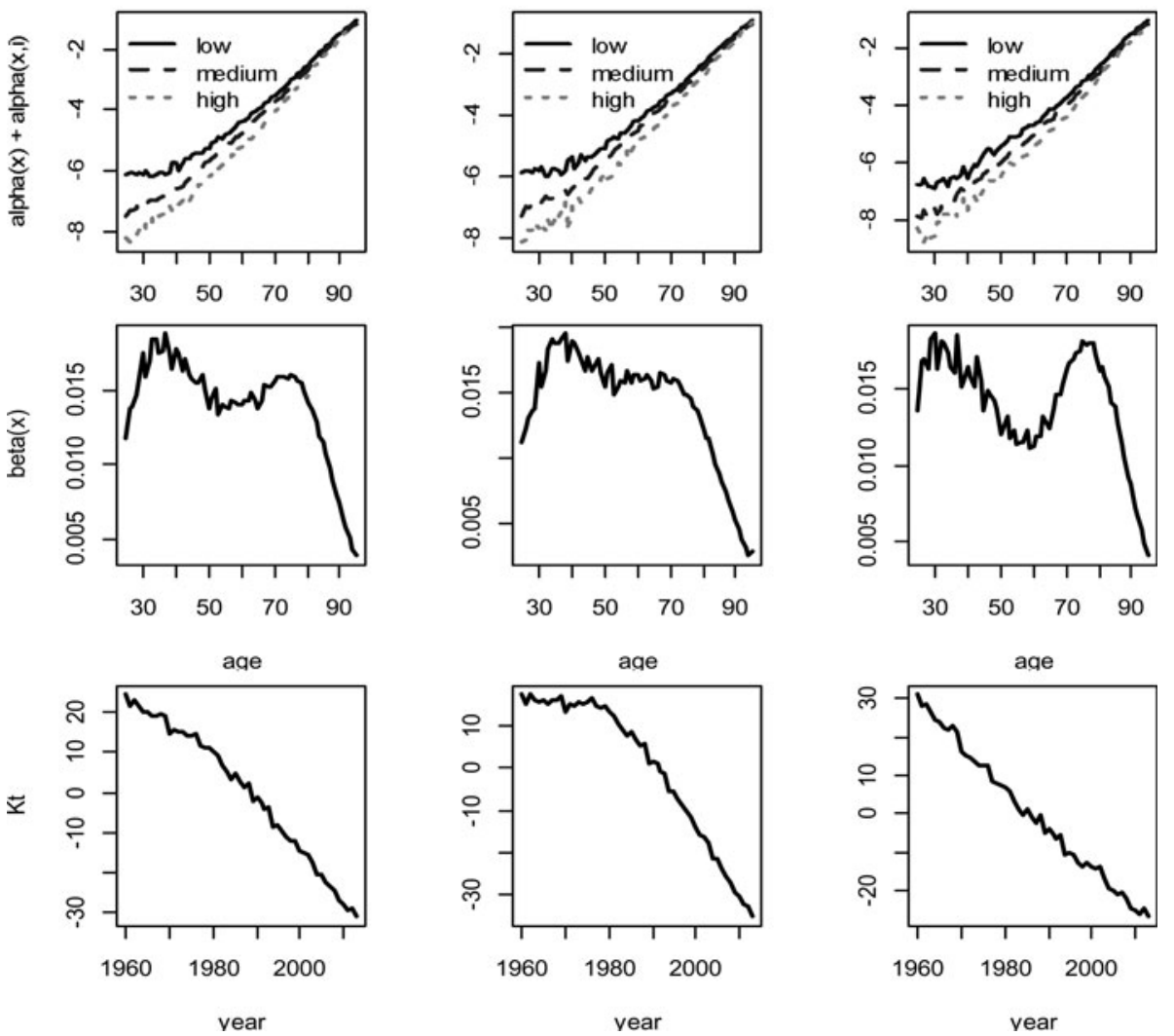

Figure A1. Parameter estimates of the 'stratified Lee-Carter' model for unisex, male and female.

Source: Authors' calculations derived from Human Mortality Database (2017) and Eurostat Database (2017).

- Economic annuity divisor ${ }^{26}$

According to Swedish Pensions Agency (2019), the formula for the demographic annuity divisor is modified to get the formula for the economic divisor. The economic divisor at retirement age $x_{e}+n$ in year $t+n$ on a birth cohort basis, denoted by

\footnotetext{
${ }^{26}$ See formula B.7.5 in Appendix B, Swedish Pensions Agency (2019).
} 
$E D_{\left(x_{e}+n, t+n\right)}$, is calculated as

$$
E D_{\left(x_{e}+n, t+n\right)}=\frac{l_{\left(x_{e}+n, t+n\right)}^{*}}{l_{\left(x_{e}+n, t+n\right)}^{*}}+\sum_{k=1}^{m-1} \frac{l_{\left(x_{e}+n+k, t+n+k\right)}^{*}}{l_{\left(x_{e}+n, t+n\right)}^{*}} \cdot \prod_{h=0}^{k-1}\left(1+r_{t+n+h}^{\prime}\right)^{-1}
$$

where

$$
l_{\left(x_{e}+n+k, t+n+k\right)}^{*}=l_{\left(x_{e}+n+k, t+n+k\right)} \cdot \bar{P}_{\left(x_{e}+n, t+n\right)} \cdot \prod_{h=0}^{k-1}\left(1+\lambda_{t+n+h}\right) .
$$

$l_{\left(x_{e}+n+k, t+n+k\right)}^{*}$ represents the total pension disbursements at time $t+n+k$ for all retirees at age $x_{e}+n+k$;

$\bar{P}_{\left(x_{e}+n, t+n\right)}$ is the average initial pension at retirement age, and the amount of pension benefit is indexed.

\section{B. Procedure to model and forecasting mortality rates across subpopulation using the 'stratified Lee-Carter' model}

We fit the 'stratified Lee-Carter' model presented in equation (3) for unisex, male and female groups separately by the method of maximum likelihood. The resulting parameter estimates are shown graphically in Figure A1. Then, the singleperiod mortality index $K_{t}$ is forecasted by a univariate autoregressive integrated moving average (ARIMA) process and is used to generate projected life tables.

The Akaike Information Criterion (AIC), Bayesian Information Criterion (BIC) and Root Mean Square Error (RMSE) are used to evaluate the best model that fits the historical data. The estimated parameters, their standard errors and values of goodness-of-fit statistics for unisex and both genders appear in Table A1. The $t$-statistics of all parameters are statistically significant, and the residual plots guide us towards retaining the chosen models. Thus, the time series of index $K_{t}$ for all population (unisex) and female are modelled by an ARIMA $(0,1,1)$ process:

$$
K_{t}=K_{t-1}+\lambda+\varepsilon_{t}+\theta_{1} \varepsilon_{t-1}
$$

while, for males, the model is as an ARIMA $(1,1,2)$ process:

$$
K_{t}=K_{t-1}+\lambda+\varepsilon_{t}+\phi_{1}\left(K_{t-1}-K_{t-2}\right)+\theta_{1} \varepsilon_{t-1}+\theta_{2} \varepsilon_{t-2}
$$

where the constant $\lambda$ indicates the average annual change of $K_{t}, \theta_{j}$ represents the $j^{\text {th }}$ moving average parameter, $\phi_{j}$ is the $j^{\text {th }}$ autoregressive and the error term $\varepsilon_{t}$ is normally distributed with zero mean and variance $\sigma^{2}$.

Next, the $\operatorname{ARIMA}(0,1,1)$ for unisex and female mortality and the $\operatorname{ARIMA}(1,1,2)$ for male mortality are used to generate the forecasts of the mortality index $K_{t}$ during the period 2014-2083. Figure A2 shows the past values of $K_{t}$ along with the projected values and associated $95 \%$ confidence intervals for unisex, male and female, respectively.

The estimated parameters from the 'stratified Lee-Carter' model in equation (3) are used to compute estimated age- and gender-specific mortality rates by subgroup $i$ in 2013 as follows:

$$
\hat{m}_{x, 2013}^{i}=\exp \left(\hat{\alpha}_{x}+\hat{\alpha}_{x}^{i}+\hat{\beta}_{x} \hat{K}_{2013}\right)
$$

Also, given the above estimated mortality rates $\hat{m}_{x, 2013}^{i}$ and the resulting forecasts of $\left\{\tilde{K}_{2013+s}: s=1,2, \ldots, 70\right\}$, the forecasted mortality rates for subpopulation $i$ are calculated as

$$
\tilde{m}_{x, 2013+s}^{i}=\hat{m}_{x, 2013}^{i} \exp \left\{\hat{\beta}_{x}\left(\tilde{K}_{2013+s}-\hat{K}_{2013}\right)\right\} .
$$

The projected mortality rates $m_{x, t}^{i}$ are converted into $q_{x, t}^{i}$, i.e., probability of an individual aged $x$ in the calendar year $t$ and subgroup $i$ dying within one year (also called the one-year probability of death). These probabilities are used to construct the life tables.

Let $f_{x}$ be the average number of years lived within the age interval $[x, x+1)$ for people dying at that age. Following Renshaw and Haberman (2003) and Wilmoth et al. (2007), we fix $f_{x}=1 / 2$ for all single ages. Hence, the approximation of 
Table A1. Parameters estimation of the $\operatorname{ARIMA}(p, d, q)$ model

\begin{tabular}{|c|c|c|c|c|c|c|c|c|c|}
\hline \multirow[b]{2}{*}{ Variable } & \multicolumn{3}{|c|}{ Unisex $\operatorname{ARIMA}(0,1,1)$} & \multicolumn{3}{|c|}{ Male ARIMA $(1,1,2)$} & \multicolumn{3}{|c|}{ Female $\operatorname{ARIMA}(0,1,1)$} \\
\hline & Coeff. & Std. Error & $t$-Stat & Coeff. & Std. Error & $t$-Stat & Coeff. & Std. Error & $t$-Stat \\
\hline$\lambda$ & -1.03 & 0.09 & -11.23 & -0.92 & 0.47 & -1.98 & -1.08 & 0.05 & -20.64 \\
\hline$\theta_{1}$ & -0.47 & 0.10 & -4.71 & -1.43 & 0.12 & -11.83 & -0.72 & 0.10 & -7.12 \\
\hline$\theta_{2}$ & - & - & - & 0.61 & 0.09 & 6.62 & - & - & - \\
\hline$\phi_{1}$ & - & - & - & 0.95 & 0.05 & 18.84 & - & - & - \\
\hline$\sigma^{2}$ & 1.62 & & & 1.40 & & & 1.80 & & \\
\hline log-likelihood & -87.01 & & & -82.90 & & & -90.05 & & \\
\hline AIC & 180.01 & & & 175.79 & & & 186.11 & & \\
\hline $\mathrm{BIC}$ & 185.92 & & & 185.64 & & & 192.02 & & \\
\hline RMSE & 1.235 & & & 1.128 & & & 1.302 & & \\
\hline
\end{tabular}

Source: Authors' calculations.

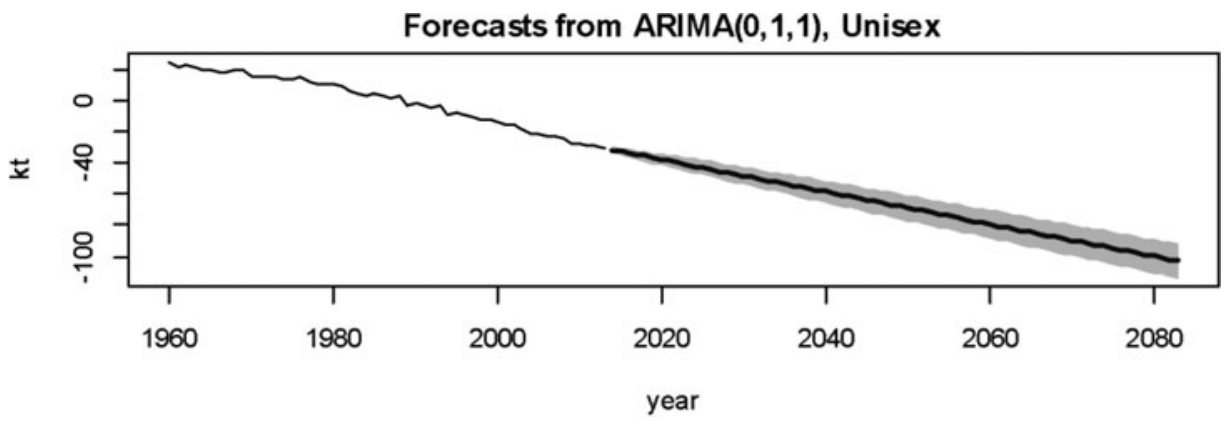

Forecasts from $\operatorname{ARIMA}(1,1,2)$, Male

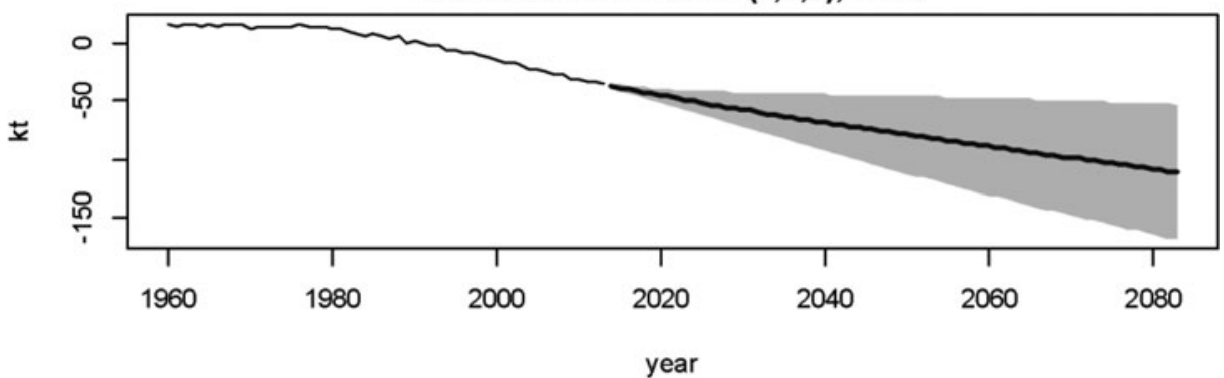

Forecasts from ARIMA(0,1,1), Female

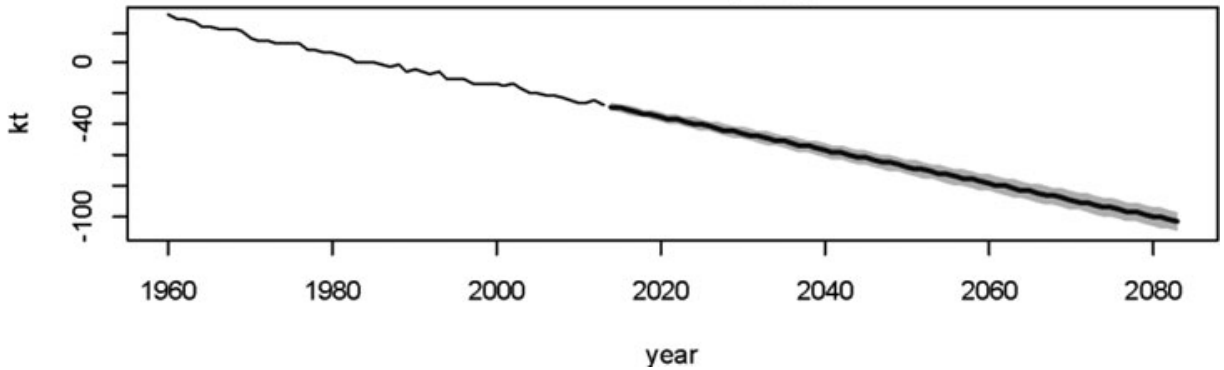

Figure A2. Forecasts of the mortality index $K_{t}$ with $95 \%$ confident interval. Source: Authors' calculations.

Note: The prediction intervals are not used in our analysis but we are aware that these are very narrow in some cases. This is a feature of some of the ARIMA models selected and it would be improved by considering the effect of parameter uncertainty through the use of boot-strapping. 
Table A2. One-year probabilities of death in a dynamic context

\begin{tabular}{llllc}
\hline & $t$ & $t+1$ & $\ldots$ & $t+70$ \\
\hline 25 & $q_{25, t}^{i}$ & $q_{25, t+1}^{i}$ & $\ldots$ & $q_{25, t+70}^{i}$ \\
26 & $q_{26, t}^{i}$ & $q_{26, t+1}^{i}$ & $\ldots$ & $q_{26, t+70}^{i}$ \\
$\ldots$ & $\ldots$ & $\ldots$ & $\ldots$ & $\ldots$ \\
$x$ & $q_{x, t}^{i}$ & $q_{x, t+1}^{i}$ & $\ldots$ & $q_{x}^{i}, t+70$ \\
$x+1$ & $q_{x+1, t}^{i}$ & $q_{x+1, t+1}^{i}$ & $\ldots$ & $q_{x+1, t+70}^{i}$ \\
$\ldots$ & $\ldots$ & $\ldots$ & $\ldots$ & $q_{95, t+70}^{i}$ \\
95 & $q_{95, t}^{i}$ & $q_{95, t+1}^{i}$ & $\ldots$ & \\
\hline
\end{tabular}

Source: Authors' illustrations.

$q_{x, t}^{i}$ is expressed as

$$
q_{x, t}^{i} \cong \frac{m_{x, t}^{i}}{1+\left(1-f_{x}\right) m_{x, t}^{i}}
$$

for $x=25,26, \ldots, 94$ and $q_{95, t}^{i}=1$ in the calendar year $t=2013,2014, \ldots, 2083$.

The elements of the matrix of $q_{x, t}^{i}$ whose rows correspond to ages and columns to calendar years can be simplified as in Table A2 (Pitacco et al., 2009). For a diagonal arrangement,

$$
q_{25, t}^{i}, q_{26, t+1}^{i}, \ldots, q_{25+s, t+s}^{i}, \ldots
$$

corresponding to a sequence of cohort life tables, with each table referring to the cohort born in year $t-25$. We use the values of $\left\{q_{25,2013}^{i}, q_{26,2014}^{i}, \ldots, q_{95,2083}^{t}\right\}$ to construct the subgroup-specific projected cohort life tables of an individual aged 25 in 2013 (equivalent to a life who was born in 1988).

Let $p_{x}^{i}$ be the probability that an individual in subgroup $i$ survives from age $x$ to $x+1$ to complete the subgroup-specific life table calculations. Therefore,

$$
p_{x}^{i}=1-q_{x}^{i}
$$

for all ages $x$.

Let the radix of the life table be $l_{25}^{i}=100,000$. Then, the number of survivors at age $x$ is

$$
l_{x, t}^{i}=l_{25}^{i} \cdot \prod_{h=25}^{x-1} p_{h}^{i}
$$

and the distribution of deaths by age in the life table population is

$$
d_{x}^{i}=l_{x}^{i} \cdot q_{x}^{i}
$$

Lastly, the projected cohort subgroup-specific life tables for the people who were born in 1988 are constructed to calculate the money's worth ratio and the unisex life table is used to compute the unisex (average) annuity divisors.

Cite this article: Boado-Penas MdelC, Haberman S, Naka P (2022). Fairness and annuity divisors for notional defined contribution pension schemes. Journal of Pension Economics and Finance 21, 143-167. https://doi.org/10.1017/ S1474747220000311 